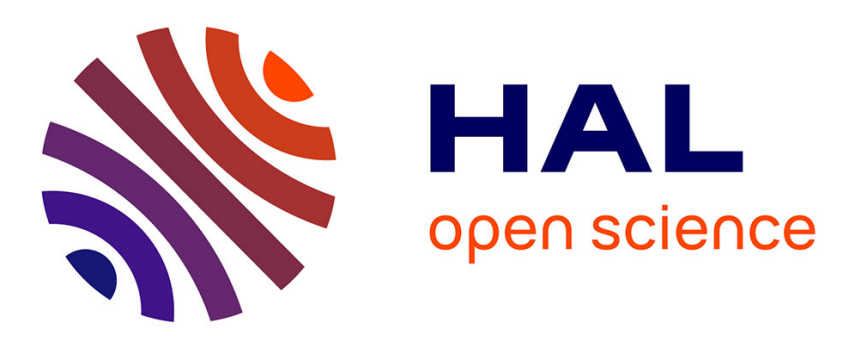

\title{
Carbon Dioxide Distribution, Origins, and Transport Along a Frontal Boundary During Summer in Mid-Latitudes
}

Arkayan Samaddar, Sha Feng, Thomas Lauvaux, Zachary R. Barkley, Sandip Pal, Kenneth J. Davis

\section{To cite this version:}

Arkayan Samaddar, Sha Feng, Thomas Lauvaux, Zachary R. Barkley, Sandip Pal, et al.. Carbon Dioxide Distribution, Origins, and Transport Along a Frontal Boundary During Summer in MidLatitudes. Journal of Geophysical Research: Atmospheres, 2021, 126 (9), 10.1029/2020JD033118. hal-03230875

\section{HAL Id: hal-03230875 https://hal.science/hal-03230875}

Submitted on 14 Jun 2021

HAL is a multi-disciplinary open access archive for the deposit and dissemination of scientific research documents, whether they are published or not. The documents may come from teaching and research institutions in France or abroad, or from public or private research centers.
L'archive ouverte pluridisciplinaire HAL, est destinée au dépôt et à la diffusion de documents scientifiques de niveau recherche, publiés ou non, émanant des établissements d'enseignement et de recherche français ou étrangers, des laboratoires publics ou privés. 


\section{JGR Atmospheres}

\section{RESEARCH ARTICLE \\ 10.1029/2020JD033118 \\ Key Points: \\ Carbon Dioxide Distribution, Origins, and Transport Along a Frontal Boundary During Summer in Mid-Latitudes}

- High resolution simulation of a cold front passage captures the narrow band of elevated $\mathrm{CO}_{2}$ ahead of the cold front

- $\mathrm{CO}_{2}$ inflow from the continental boundaries along with biogenic fluxes create the summertime frontal $\mathrm{CO}_{2}$ distribution

- Horizontal and vertical advection dominate atmospheric $\mathrm{CO}_{2}$ transport along the frontal boundary

Supporting Information:

Supporting Information may be found in the online version of this article.

Correspondence to:

A. Samaddar and S. Feng,

arkayan@psu.edu;

sfeng@pnnl.gov

Citation:

Samaddar, A., Feng, S., Lauvaux, T., Barkley, Z. R., Pal, S., \& Davis, K. J. (2021). Carbon dioxide distribution, origins, and transport along a frontal boundary during summer in mid-latitudes. Journal of Geophysical Research: Atmospheres, 126, e2020JD033118. https://doi. org/10.1029/2020JD033118

Received 18 MAY 2020

Accepted 4 FEB 2021

Author Contributions:

Conceptualization: Arkayan

Samaddar, Sha Feng, Thomas Lauvaux,

Kenneth J. Davis

Data curation: Sandip Pal, Kenneth J. Davis

Formal analysis: Arkayan Samaddar, Sha Feng, Thomas Lauvaux, Zachary R. Barkley, Sandip Pal, Kenneth J. Davis Funding acquisition: Kenneth J. Davis

Investigation: Arkayan Samaddar, Sha Feng, Thomas Lauvaux, Zachary R. Barkley, Sandip Pal, Kenneth J. Davis Methodology: Arkayan Samaddar, Sha Feng, Thomas Lauvaux, Zachary R. Barkley, Sandip Pal, Kenneth J. Davis Project Administration: Sha Feng, Thomas Lauvaux, Kenneth J. Davis

(C) 2021. American Geophysical Union. All Rights Reserved.

\author{
Arkayan Samaddar $^{1}$ (D), Sha Feng ${ }^{1,2}$ (D), Thomas Lauvaux ${ }^{3}$ (D), Zachary R. Barkley ${ }^{1}$ (D), \\ Sandip $\mathrm{Pal}^{4}$ (D), and Kenneth J. Davis ${ }^{1,5}$ (D) \\ ${ }^{1}$ Department of Meteorology and Atmospheric Science, The Pennsylvania State University, University Park, PA, USA, \\ ${ }^{2}$ Now at Atmospheric Sciences and Global Change Division, Pacific Northwest National Laboratory, Richland, WA, \\ USA, ${ }^{3}$ Laboratoire des Sciences du Climat et de l'Environnement, CEA, CNRS, UVSQ/IPSL, Université Paris-Saclay, \\ Orme des Merisiers, Gif-sur-Yvette Cedex, France, ${ }^{4}$ Department of Geosciences, Texas Tech University, Lubbock, TX, \\ USA, ${ }^{5}$ Earth and Environmental Systems Institute, The Pennsylvania State University, University Park, PA, USA
}

Abstract Synoptic weather systems are a major driver of spatial gradients in atmospheric $\mathrm{CO}_{2}$ mole fractions. During frontal passages, air masses from different regions meet at the frontal boundary creating significant gradients in $\mathrm{CO}_{2}$ mole fractions. We quantitatively describe the atmospheric transport of $\mathrm{CO}_{2}$ mole fractions during a mid-latitude cold front passage and explore the impact of various sources of $\mathrm{CO}_{2}$ We focus here on a cold front passage over Lincoln, Nebraska on August 4th, 2016 observed by aircraft during the Atmospheric Carbon and Transport-America campaign. A band of air with elevated $\mathrm{CO}_{2}$ was located along the frontal boundary. Observed and simulated differences in $\mathrm{CO}_{2}$ across the front were as high as $25 \mathrm{ppm}$. Numerical simulations using Weather Research and Forecasting Model with Chemistry at cloud resolving resolutions $\left(3 \mathrm{~km}\right.$ ), coupled with $\mathrm{CO}_{2}$ surface fluxes and boundary conditions from CarbonTracker (CT-NRTv2017x), were performed to explore atmospheric transport at the front. Model results demonstrate that the frontal $\mathrm{CO}_{2}$ difference in the upper troposphere can be explained largely by inflow from outside of North America. This difference is modified in the atmospheric boundary layer and lower troposphere by continental surface fluxes, dominated in this case by biogenic and fossil fuel fluxes. Horizontal and vertical advection are found to be responsible for the transport of $\mathrm{CO}_{2}$ mole fractions along the frontal boundary. We show that cold front passages lead to large $\mathrm{CO}_{2}$ transport events including a significant contribution from vertical advection, and that midcontinent frontal boundaries are formed from a complex mixture of $\mathrm{CO}_{2}$ sources.

\section{Introduction}

Atmospheric $\mathrm{CO}_{2}$ mole fractions have changed from $280 \mathrm{ppm}$ during the pre-industrial period (circa. 1750) to present day mole fractions of $414 \mathrm{ppm}$ (www.esrl.noaa.gov/gmd/ccgg/trends/). Over the last decade, the rate of increase in global atmospheric $\mathrm{CO}_{2}$ mole fractions has risen from $1.8 \mathrm{ppm} /$ year in 2008 to $2.4 \mathrm{ppm} /$ year in 2018. These changes in atmospheric $\mathrm{CO}_{2}$ have been linked to an increase in fossil fuel usage (Edenhofer et al., 2014; Skeie et al., 2011) and land use change (Houghton et al., 2012). About 55\% of the $\mathrm{CO}_{2}$ emissions are currently absorbed into oceans or terrestrial ecosystems (Friedlingstein et al., 2019; Le Quéré et al., 2018). In order to close the budget of atmospheric $\mathrm{CO}_{2}$, the driving mechanisms of sources and sinks of $\mathrm{CO}_{2}$ from continental surfaces and oceans need to be better quantified (Le Quéré et al., 2018). Studies have shown that northern hemisphere terrestrial ecosystems are a significant part of the terrestrial sink (Denning et al., 1995; Tans et al., 1990). However, uncertainties in estimates of global carbon sources and sinks exist due to lack of knowledge regarding primary drivers of the land sink (Huntzinger et al., 2017). Peylin et al. (2002) and Xiao et al. (2014) show that one of the key uncertainties in regional carbon flux estimates comes from errors in representation of atmospheric transport. Bastos et al. (2020) have investigated the sources of uncertainty in global scale models in the Global Carbon Budget (Le Quéré et al., 2018) and have found that among other factors, more in-situ observations help reduce uncertainties in atmospheric inversions.

Atmospheric transport models are used to determine sources and sinks of $\mathrm{CO}_{2}$ through the process of inversion-linking $\mathrm{CO}_{2}$ mole fractions in the atmosphere to sources and sinks at the surface (Enting et al., 1995). 
Resources: Sha Feng, Thomas Lauvaux, Sandip Pal, Kenneth J. Davis Software: Arkayan Samaddar, Sha Feng, Thomas Lauvaux, Kenneth J. Davis

Supervision: Sha Feng, Thomas Lauvaux, Kenneth J. Davis Validation: Arkayan Samaddar, Sha Feng, Kenneth J. Davis

Visualization: Arkayan Samaddar Writing - original draft: Arkayan Samaddar, Sha Feng, Thomas Lauvaux, Kenneth J. Davis

Writing - review \& editing: Arkayan Samaddar, Sha Feng, Thomas Lauvaux, Zachary R. Barkley, Sandip Pal, Kenneth J. Davis
In order for the inversion process to be accurate, these numerical transport models need to infer $\mathrm{CO}_{2}$ sources and sinks with high accuracy (Gurney et al., 2002). Evaluating the numerical models using $\mathrm{CO}_{2}$ observation help determine the uncertainty in the ability of the models to reproduce the carbon cycle (Agustí-Panareda et al., 2019; H. W. Chen et al., 2019; Chevallier et al., 2019; Díaz Isaac et al., 2014, 2018).

Differences in the representation of transport processes within individual numerical models can lead to a biased representation of $\mathrm{CO}_{2}$ (Houweling et al., 2010; Law et al., 1996; Schuh et al., 2019). Errors in the representation of atmospheric boundary layer (ABL) dynamics (vertical mixing heights and horizontal wind profiles) in numerical models results in errors in inverse estimates of $\mathrm{CO}_{2}$ (Lauvaux \& Davis, 2014). Further studies evaluating both global and regional models also found that the simulated ABL depth in a numerical model has significant influence on the $\mathrm{CO}_{2}$ distribution, and errors in the estimation of ABL depth are a major source of uncertainty in atmospheric transport representation (Geels et al., 2007). Synoptic scale weather events are an important part of atmospheric $\mathrm{CO}_{2}$ transport, and the representation of synoptic weather in numerical models is not addressed in studies focused on global scale and ABL evaluations.

The performance of regional and global models in capturing the synoptic scale variability of atmospheric $\mathrm{CO}_{2}$ distribution has been evaluated (Law et al., 2008). Patra et al. (2008) and Sarrat et al. (2007) evaluated multiple global and regional scale numerical models and found that they were able to represent the observed synoptic scale $\mathrm{CO}_{2}$ variability from tower and aircraft measurements. In order to improve the representation of atmospheric transport, the above studies suggest the use of higher horizontal and vertical resolution numerical models coupled with $\mathrm{CO}_{2}$ fluxes with high temporal and spatial resolution (Agustí-Panareda et al., 2019; Geels et al., 2007). Numerical models running at global scale resolutions ( $>100$ s of $\mathrm{km}$ ) represent mesoscale and microscale weather events through parameterizations of physical transport processes (Carvalho et al., 2014). A regional model study in east Asia has shown that numerical models running at higher resolutions than global models ( $27 \mathrm{~km}$ horizontal grid resolution) were able to reproduce observed changes in atmospheric $\mathrm{CO}_{2}$ mole fractions due to mesoscale weather systems (Ballav et al., 2012). The study also recommended the implementation of higher resolution transport models to better represent diurnal and synoptic variability of $\mathrm{CO}_{2}$ as well as represent the changes in atmospheric $\mathrm{CO}_{2}$ mole fractions by synoptic weather events.

Cold front passages are an example of synoptic scale events. Studies have shown that cold front passages have created gradients in atmospheric $\mathrm{CO}_{2}$ mole fractions at the frontal boundary (Hurwitz et al., 2004; Lee et al., 2012). In Hurwitz et al. (2004), tall tower observations at Park Falls, Wisconsin, have studied four cold front passages over multiple seasons and shown that a summertime cold front passage resulted in changes in $\mathrm{CO}_{2}$ mole fractions in the ABL. These changes were attributed to a pre-existing meridional gradient that was advected into the region as well as nearby biospheric fluxes. Horizontal advection and vertical mixing were hypothesized as the transport processes driving the changes in $\mathrm{CO}_{2}$ mole fractions. Lee et al. (2012) reported that changes in $\mathrm{CO}_{2}$ mole fractions caused by a cold front passage were greater than the gradients created due to typical diurnal variations on fair weather days. The changes in $\mathrm{CO}_{2}$ mole fractions were dependent on the direction of cold front passage as well as the accumulation of $\mathrm{CO}_{2}$ along the frontal boundary caused by wind shear and deformational flow. The Atmospheric Carbon and Transport (ACT)-America flight campaign provides a unique data set of aircraft measurement across multiple cold fronts over continental United States (Pal \& Davis, 2020). Continuous aircraft measurements across frontal boundaries captured the difference in $\mathrm{CO}_{2}$ mole fractions between the warm and cold sectors for multiple frontal passages (Davis et al., 2018). For summertime cold fronts, a region of elevated $\mathrm{CO}_{2}$ mole fractions was found along the frontal boundary (Pal et al., 2020). Mesoscale dynamics were seen to modulate the width and magnitude of the enhanced $\mathrm{CO}_{2}$ region. These studies highlighted the significance but did not quantify transport or simulate the processes leading to these structures.

The impact of synoptic scale events on atmospheric $\mathrm{CO}_{2}$ mole fractions has also been simulated using various global and regional scale numerical models. Previous studies have shown that there is a correlation between atmospheric transport variables and biospheric $\mathrm{CO}_{2}$ fluxes at synoptic scales resulting in large scale spatial gradients (Denning et al., 1995). Geels et al. (2004) found that the variability of $\mathrm{CO}_{2}$ mole fractions in summer was highly correlated to the continental biospheric fluxes of $\mathrm{CO}_{2}$ over the region. The horizontal transport of upstream features in $\mathrm{CO}_{2}$ mole fractions also contributes significantly to the synoptic-scale $\mathrm{CO}_{2}$ distribution. These interactions have been further explored in Chan et al. (2004), highlighting the response 
of simulated $\mathrm{CO}_{2}$ mole fractions to changes in atmospheric conditions. Suppression of photosynthesis due to cloud cover ahead of the cold front resulted in increased $\mathrm{CO}_{2}$ mole fractions. Cold front passage introduced air with elevated $\mathrm{CO}_{2}$ mole fractions near the surface, and vertical mixing in the warm sector was able to lift surface level $\mathrm{CO}_{2}$ to the troposphere. Chan et al. (2004) also found that $\mathrm{CO}_{2}$ gradients between 1 and $10 \mathrm{ppm} / 100 \mathrm{~km}$ can be created by mesoscale horizontal and vertical transport processes within a day. In order to further understand the mechanisms driving the transport of atmospheric $\mathrm{CO}_{2}$, a budget equation was developed (Bakwin et al., 2004). Using this equation on cold front passages showed that wind shear and deformational flow near the frontal boundary created strong $\mathrm{CO}_{2}$ gradients that were advected horizontally along with the front (Parazoo et al., 2008). Studies have shown that for cold front passages, simulated $\mathrm{CO}_{2}$ mole fractions are influenced by local surface fluxes along with horizontal and vertical transport processes over a timescale of a few days (Wang et al., 2007). Through these studies, it was found that the impact of cold front passages on the distribution of $\mathrm{CO}_{2}$ is attributed to local fluxes of $\mathrm{CO}_{2}$ interacting with upstream $\mathrm{CO}_{2}$ gradients along the frontal boundary through horizontal and vertical transport.

Based on the recommendations from the previous studies investigating synoptic $\mathrm{CO}_{2}$ variability, we use high-resolution Weather Research and Forecasting Model with Chemistry (WRF-Chem; Skamarock et al., 2008) simulation operating at 27, 9 , and $3 \mathrm{~km}$ resolutions. The resolution of $3 \times 3 \mathrm{~km}$ is capable of resolving some cloud convection (Klemp, 2006), presenting a more resolved description of frontal transport. We study a summer cold front passing over Lincoln, NE, USA using WRF-Chem v3.6.1. The transport of $\mathrm{CO}_{2}$ is quantified using a budget equation identifying contributions from horizontal and vertical advection and vertical diffusion. Aircraft observations from the ACT-America campaign are used to evaluate the performance of the numerical results. Through this study we provide a unique cloud resolving resolution view of features in atmospheric $\mathrm{CO}_{2}$ distribution during a single cold front passage. While past studies have highlighted the differences in $\mathrm{CO}_{2}$ mole fractions between the warm and cold sectors, for this cold front passage we show that along with the cross-sector difference, there is the presence of a narrow band of elevated $\mathrm{CO}_{2}$ along the frontal boundary. We show that while biogenic sources and large scale inflow from the domain boundaries influenced the cross-frontal difference in $\mathrm{CO}_{2}$ mole fractions, the narrow band of elevated $\mathrm{CO}_{2}$ was primarily driven by biogenic sources. Using a $\mathrm{CO}_{2}$ budget equation (Bakwin et al., 2004; Parazoo et al., 2008), we highlight the interaction of horizontal advection, vertical advection, and vertical diffusion with $\mathrm{CO}_{2}$ mole fractions during the cold front passage.

The current study is structured as follows - the data and methods section describe the numerical model and the tools and analysis methods used for the current study. The results section characterizes the capabilities of the numerical modeling system and describes the $\mathrm{CO}_{2}$ distribution along the frontal boundary and its evolution with time. Transport of $\mathrm{CO}_{2}$ is broken out by terms in the conservation equation, including the impact of model grid-resolution on the representation of $\mathrm{CO}_{2}$ transport. The final section highlights the implications of the current study for the broader scientific community.

\section{Data and Numerical Framework}

\subsection{ACT-America Aircraft Measurements}

The ACT-America mission is a NASA Earth Venture Suborbital mission designed to improve atmospheric inverse estimates of greenhouse gas (GHG) fluxes. One objective is to quantify and reduce atmospheric GHG transport uncertainties (Davis et al., 2018). Two aircraft, a NASA Wallops C-130 Hercules and a NASA Langley B200 King Air, collected remote and in situ measurements in the boundary layer and free troposphere. During frontal passages, flight paths were designed to make measurements in both the warm and cold sectors by crossing frontal systems at multiple levels. Multiple vertical profiles were also collected on both sides of the front. In situ $\mathrm{CO}_{2}$ measurements from the $\mathrm{B} 200$ and $\mathrm{C}-130$ aircraft were collected using a PICARRO 2401-m spectrometer (Digangi et al., 2018) along with atmospheric state variables. Data sets are described by Davis et al. (2018). In the current study, we evaluated the performance of the numerical model using in-situ measurements from the ACT-America aircraft on August 4th, 2016. 


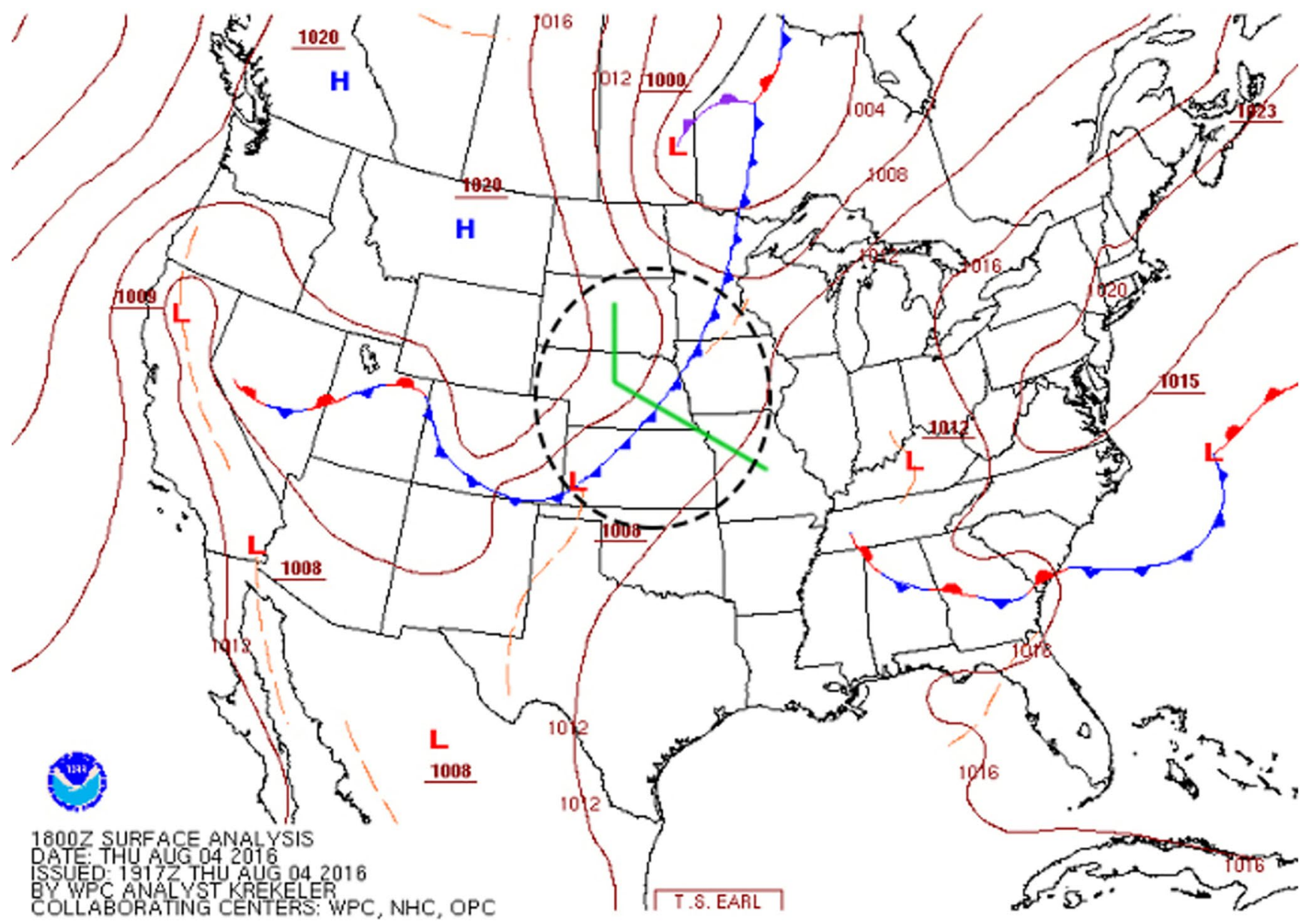

Figure 1. Synoptic map over continental United States on August 4th, 2016 at 18Z. The cold front studied is highlighted in the black dashed circle, and the green line shows the approximate flight path for the ACT-America aircraft. Courtesy: NOAA/National Weather Service.

\subsection{Cold Front Passage on August 4th, 2016}

The summer 2016 flight campaign was in the Midwest region of the United States from August 1st to August 17th. A cold front crossed south-eastern Nebraska, Iowa and northern Kansas (located within the $3 \mathrm{~km}$ simulation domain) from August 4th $18 \mathrm{Z}$ to August 6th 09Z. Figure 1 shows the synoptic map for the frontal passage with the flight track overlay. The low-pressure center of the front was located over Manitoba in Canada. The cold front passage was characterized by a $170^{\circ}$ change in wind directions at the frontal boundary-northerly winds to southerly winds. The Lincoln airport station (KLNK) recorded that the daytime mean temperature dropped by $12 \mathrm{~K}$ between the 4 th and 5 th of August. The change in the air mass over the station was also accompanied by a 10\% decrease in relative humidity and a $10 \mathrm{hPa}$ drop in surface pressure. To capture the gradients in $\mathrm{CO}_{2}$ mole fractions across the frontal boundary, the aircraft crossed the front at multiple altitudes ( $300 \mathrm{~m}, 3 \mathrm{~km}, 5 \mathrm{~km}$, and $8 \mathrm{~km} \mathrm{MSL}$ ) on August 4th between $16 \mathrm{Z}$ and 21Z. Vertical profiles were also taken at multiple locations in the warm and cold sector. The aircraft recorded a 25 ppm change in $\mathrm{CO}_{2}$ over a horizontal span of $40 \mathrm{~km}$ while crossing the frontal boundary in the ABL (Pal et al., 2020). Smaller cross-frontal mole fraction differences of the same sign were observed in the free troposphere (Pal et al., 2020).

\subsection{Model Description}

For the current study, we used the WRF-Chem ver. 3.6.1 (Skamarock et al., 2008). We ran the model with one-way nesting via three nested domains with spatial grid resolutions of 27, 9, and $3 \mathrm{~km}$ respectively, using 


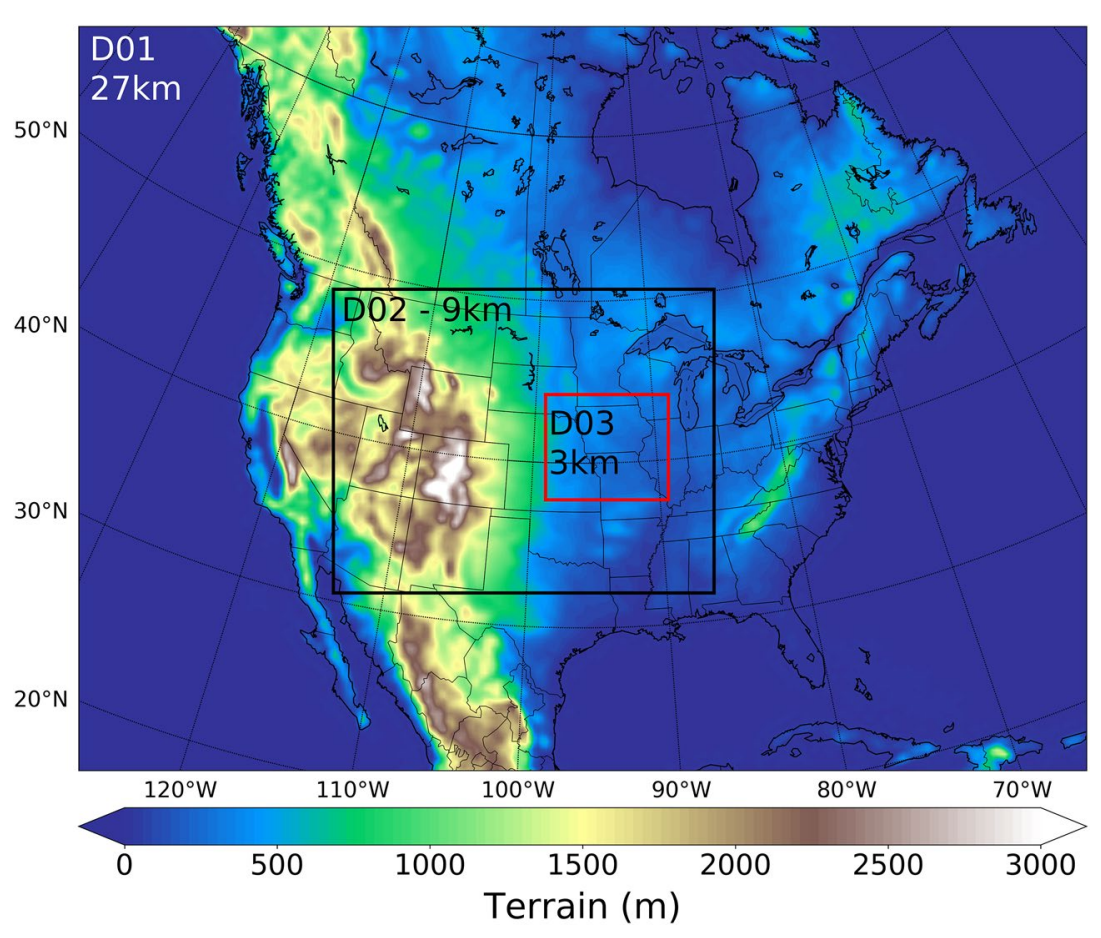

Figure 2. Domains used for the WRF-Chem model simulations, shown with contours of terrain height in meters above sea level. The map shows the $27 \mathrm{~km}$ resolution domain (D01), the black inner box shows the $9 \mathrm{~km}$ domain (D02), and the innermost red box shows the $3 \mathrm{~km}$ domain (D03).

WRF-Chem with a modification to include $\mathrm{CO}_{2}$ as a passive tracer (Lauvaux et al., 2012). Figure 2 shows the arrangement of the nested domains as used in WRF-Chem. Vertical grid resolution is kept constant across the domains with 51 terrain-following eta levels from the surface to the top of the atmosphere (at $100 \mathrm{hPa}$ ). The vertical grids are staggered with 29 levels forming a higher density grid under $2 \mathrm{~km}$ above ground level (AGL), with greater spacing above. The first vertical level has an elevation of $8 \mathrm{~m}$ above ground level.

The simulations were initialized with meteorological driver data from 6-hourly ERA-Interim (Dee et al., 2011) outputs with a reduced Gaussian grid with approximately uniform $79 \mathrm{~km}$ spacing for surface and other grid-point fields (Berrisford et al., 2011) and NCEP high-resolution $\left(0.083^{\circ} \times 0.083^{\circ}\right)$ SST data. Model physics are summarized in Table 1. We output WRF-Chem hourly for the period from July to August 2016, in which the model was re-initialized every 5 days and with 12-h meteorological spin-up.

Table 1

Parameterization Options Used for WRF-Chem Simulations

\begin{tabular}{ll}
\hline Option & \multicolumn{1}{c}{ Parameter } \\
\hline Microphysics & Thompson (Thompson et al., 2008) \\
Boundary Layer Scheme & MYNN2 (Nakanishi \& Niino, 2006) \\
Longwave radiation & RRTMG longwave scheme (Iacono et al., 2008) \\
Shortwave radiation & RRTMG shortwave scheme (Iacono et al., 2008) \\
Land surface & Unified Noah land-surface model (F. Chen \& Dudhia, 2001) \\
Cumulus & Kain-Fritsch (new Eta) scheme (Kain, 2004), \\
Parameterization & for the 27 and 9 km resolution domains \\
\hline Abbreviation: WRF-Chem,Weather Research and Forecasting Model with Chemistry.
\end{tabular}




\section{4. $\mathrm{CO}_{2}$ Simulations}

WRF-Chem transport was coupled with $\mathrm{CO}_{2}$ fluxes from the CarbonTracker Near Real Time v2017 (CTNRT.v2017) (Peters et al., 2007), hereafter referred to as CT-NRT.v2017. $\mathrm{CO}_{2}$ is simulated as a passive tracer in the current study—similar to setups described in prior studies (Butler et al., 2020; Feng, Lauvaux, Keller, et al., 2019; Feng, Lauvaux, Davis, et al., 2019). CT-NRT.v2017 provided surface fluxes as well as lateral boundary conditions. Within the WRF-Chem framework, these surface fluxes are tracked as individual tracers simulating fossil fuel emissions, biogenic fluxes, oceanic fluxes, and biomass burning emissions. $\mathrm{CO}_{2}$ inflow from CT-NRT.v2017 to the boundaries of the WRF-Chem domains are tracked separately as lateral boundary condition tracers with the consideration of $\mathrm{CO}_{2}$ mass conservation. Horizontal and vertical interpolations were applied using weights based on the pressure level differences between the two models. More details can be found in Butler et al. (2020). Thus, by considering the sum of all the individual tracers, the total atmospheric $\mathrm{CO}_{2}$ mole fractions are determined. The lateral boundary conditions have a $3^{\circ} \times 2^{\circ}$ spatial resolution and the set of surface fluxes have a $1^{\circ} \times 1^{\circ}$ resolution over the study domain. Temporally, all the fluxes are introduced as 3-hourly mean values. The simulation is initialized with an atmosphere free of $\mathrm{CO}_{2}$. Lateral boundary conditions along with surface fluxes populate the domain with $\mathrm{CO}_{2}$ while WRF-Chem transport moves it within the domain. The regional model (WRF-Chem) simulation is initialized with an atmosphere devoid of any $\mathrm{CO}_{2}$ mole fractions. Through surface emissions and inflow from the domain boundaries, $\mathrm{CO}_{2}$ is introduced using information from Carbon Tracker NRT v2017. The high resolution WRF-Chem transport acts on these mole fractions to distribute $\mathrm{CO}_{2}$ in the atmosphere. WRF-Chem was run for a month prior to the campaign period (July 2016) to ensure realistic $\mathrm{CO}_{2}$ mole fractions (approximately $410 \mathrm{ppm}$ ) in the domain atmosphere before simulating the study period (August 2016).

\subsection{Breakdown of $\mathrm{CO}_{2}$ Mole Fractions Into Components}

Within the WRF-Chem framework, the simulated atmospheric $\mathrm{CO}_{2}$ mole fractions are calculated as the sum of components from CT-NRT.v2017, which are related to the various surface fluxes of $\mathrm{CO}_{2}$ along with the lateral boundary conditions. By tracking the individual tracers, it is possible to show the interaction between atmospheric transport features created due to the cold front passage and $\mathrm{CO}_{2}$ emitted from these various sources and the boundary conditions. In the current study, the $\mathrm{CO}_{2}$ from the boundary conditions represent inflow from outside the simulation domains. These interactions can highlight which $\mathrm{CO}_{2}$ tracer is impacted the most by the frontal passage. Additionally, a footprint analysis has also been performed to trace the origins of the air masses at the frontal boundary. Thus, by combining these two analyses it is possible to determine which sources of $\mathrm{CO}_{2}$ were responsible for the atmospheric distribution during the period of frontal passage.

WRF-Chem was configured to simulate $\mathrm{CO}_{2}$ originating from fossil fuel, biogenic, oceanic, and fire surface fluxes, and boundary conditions as separate tracers. Due to negligible impacts of oceanic and fire sources on $\mathrm{CO}_{2}$ during the study period ( $<1 \mathrm{ppm}$ ), we focus only on fossil fuel, biogenic and boundary condition tracers to investigate how the transport impacts them individually and quantify their contribution to specific features such as the band of elevated $\mathrm{CO}_{2}$ mole fractions along the frontal boundary.

\section{Methods}

\subsection{Model-Data Comparison}

During the ACT-America flight campaign, $\mathrm{CO}_{2}$ mole fractions along with standard atmospheric variables (potential temperature, water vapor mole fraction etc.) were measured on both aircraft (Davis et al., 2018). Similarly, simulated values of potential temperature and $\mathrm{CO}_{2}$ mole fractions were extracted from WRFChem along the flight tracks to evaluate model performance. A limitation in this approach arose from the different time and spatial resolution of the products used. The modeled potential temperature and $\mathrm{CO}_{2}$ mole fraction values were extracted from nearest points to the observations. The aircraft data are archived with a time resolution of $5 \mathrm{~s}$ (Davis et al., 2018), while the WRF-Chem setup used has been configured with hourly output. For this evaluation, hourly model data that was closest in time to the observations were used for comparison. In order to compare aircraft measurements along constant altitude flight legs, horizontal maps were extracted from WRF-Chem at the same altitude. A transect drawn almost parallel to the flight 
path was used to compare the vertical features of the front as described by WRF-Chem and the aircraft measurements.

\subsection{Calculating $\mathrm{CO}_{2}$ Transport Terms}

As mentioned in Section 2.4, $\mathrm{CO}_{2}$ is simulated in WRF-Chem as a passive tracer. The transport of $\mathrm{CO}_{2}$ is driven by the simulated atmospheric dynamics. Previous studies (Bakwin et al., 2004; Parazoo et al., 2008) have used the scalar conservation equation:

$$
\underbrace{\frac{\partial C}{\partial t}}_{i}+\underbrace{\frac{R T}{p} \frac{F_{c}}{z_{1}}}_{i i}+\underbrace{K_{m} \frac{\partial^{2} C}{\partial z^{2}}}_{i i i}+\underbrace{w \frac{\partial c}{\partial z}}_{i v}+\underbrace{\overrightarrow{V_{H}} \cdot \nabla_{H} C}_{v}+\underbrace{g \frac{M \partial C}{\partial p}}_{v i}=0
$$

to quantify $\mathrm{CO}_{2}$ transport in the atmosphere where $C$ is the $\mathrm{CO}_{2}$ mole fractions in ppm, $F_{c}$ is the surface flux of $\mathrm{CO}_{2}, z_{1}$ is the lowest model level, $R$ is the gas constant, $T$ is the temperature, $p$ is the pressure, $K_{m}$ is the vertical eddy diffusivity coefficient, $w$ is the vertical velocity, $\overrightarrow{V_{H}}$ is horizontal velocity, $g$ is the gravity, and $M$ is the parameterized convective mass transport.

The individual terms represent the tendency in $\mathrm{CO}_{2}$ mole fractions (i), influence of surface fluxes (ii), and transport by vertical diffusion (iii), vertical advection (iv), horizontal advection (v), and cloud convection (vi).

Term (ii) acts only on the lowest model layer. The cloud convective transport term is suitable for a model with parameterized convection. In the $3-\mathrm{km}$ simulation, the convective transport is not separable from the grid-scale vertical advection and thus, in Equation 2, the new term (iv-modified) includes the vertical transport due to convection (vi) and vertical advection (iv) in Equation 1. We use lower-case $c$ to indicate the differences. We continue to refer to term (iv-modified) as vertical advection for simplicity. Thus, at elevated model level (above the first level), the equation for cloud resolving resolution models can be further reduced to:

$$
\underbrace{\frac{\partial C}{\partial t}}_{i}+\underbrace{K_{m} \frac{\partial^{2} C}{\partial z^{2}}}_{\text {iii }}+\underbrace{w \frac{\partial c}{\partial z}}_{\text {iv-modified }}+\underbrace{\overrightarrow{V_{H}} \cdot \nabla_{H} C}_{v}=0
$$

In our study, we showcase horizontal advection, vertical advection, and vertical diffusion as the transport terms representing change in $\mathrm{CO}_{2}$ mole fractions in the atmosphere. We study the impact of these terms on the distribution of $\mathrm{CO}_{2}$ along a frontal boundary. Terms from Equation 2 were calculated using 3D velocities, $\mathrm{CO}_{2}$ mole fractions, and eddy diffusivity from WRF-Chem hourly outputs.

\section{Results}

\subsection{Comparison to ACT-America Aircraft Measurements}

WRF-Chem simulated a cold front with thermal features that are consistent with the aircraft measurements. Figure 3 shows the horizontal map and vertical cross-section of potential temperature from WRFChem and aircraft measurements. In Figure $3 \mathrm{a}$ it can be seen that there is a region of warm air located in the south-west of the domain and a cold air mass to the north-west of the domain. Figure $3 \mathrm{~b}$ shows the variability in potential temperature in a vertical cross-section across the frontal boundary. The warm and cold air masses meet at $-97^{\circ}$ longitude at the surface. The vertical distribution of potential temperature shows that there is a band of warm air $(\theta>307 \mathrm{~K})$ extending from $-97^{\circ}$ to $-94^{\circ}$ longitude. This warm air mass was also present in the aircraft measurements.

Similar to potential temperature, WRF-Chem simulated wind speed and wind direction across the front that are largely consistent with the ACT-America aircraft observations. Figure 4a shows that in the ABL along the frontal boundary there is a decrease in wind speed at the frontal boundary as seen in the aircraft 
a)

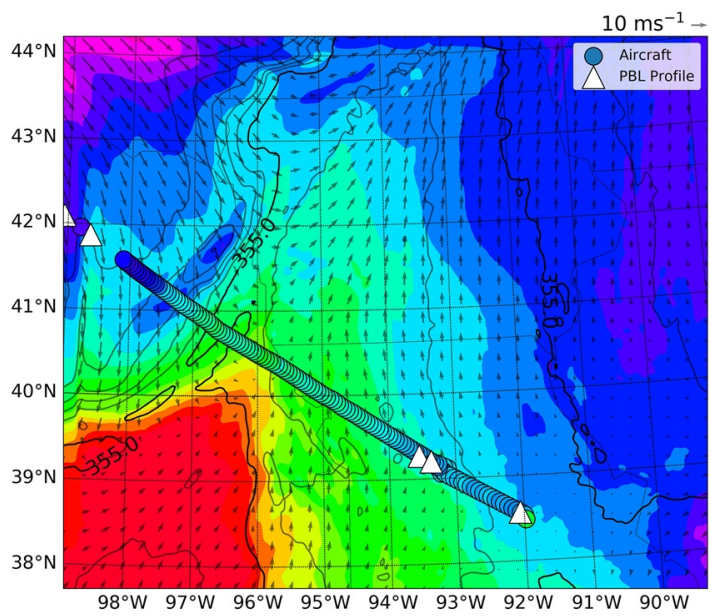

b)

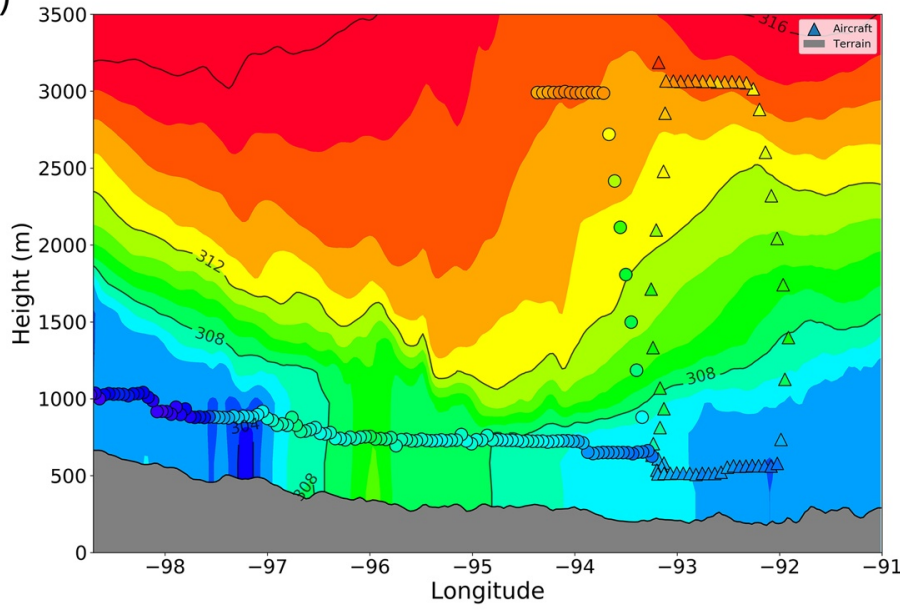

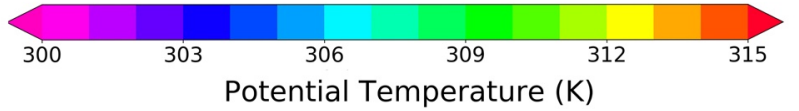

Figure 3. Comparisons of aircraft measurements to the high-resolution ( $3 \mathrm{~km}$ ) WRF-Chem simulation (at $548 \mathrm{~m}$ AGL) of potential temperature on August 4th, 2016 at 18Z. The aircraft measurements are shown as circles. Panel (a) shows simulated potential temperature overlaid with aircraft observations from approximately the same altitude, and (b) shows the vertical cross-section across the frontal boundary along the path traced by the aircraft transects. To match times with WRF-Chem outputs, aircraft measurements within $\pm 30 \mathrm{~min}$ of $18 \mathrm{Z}$ are shown. The white triangles in panel (a) show the location of vertical profiles used to calculate boundary layer depth. AGL, above ground level; WRF-Chem,Weather Research and Forecasting Model with Chemistry.

measurements and WRF-Chem; the feature is most prominent between $-97^{\circ}$ and $-96^{\circ}$ longitude and $40^{\circ}$ and $41^{\circ}$ latitude. In the cold sector, toward the northwest region of the domain, the higher wind speeds $\left(>9 \mathrm{~m} \mathrm{~s}^{-1}\right)$ measured by the aircraft were also captured by WRF-Chem. Southerly winds in the warm sector have lower wind speeds $\left(<9 \mathrm{~m} \mathrm{~s}^{-1}\right)$ in WRF-Chem as well as the aircraft measurements. WRF-Chem

a)

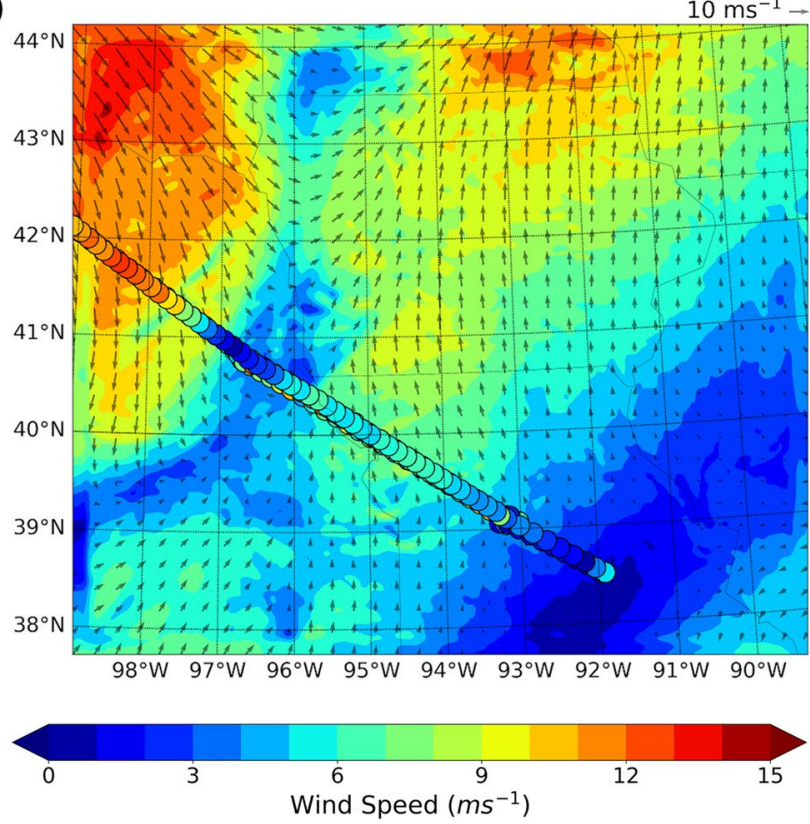

b)

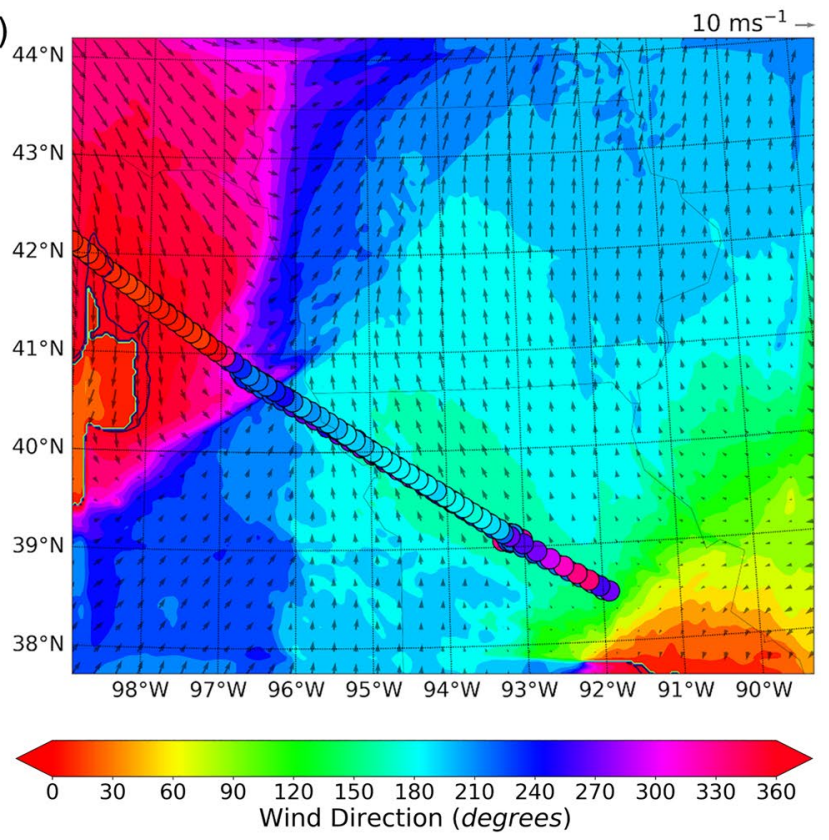

Figure 4. Comparisons of aircraft measurements to the high-resolution ( $3 \mathrm{~km})$ WRF-Chem simulation of horizontal winds on August 4 th, 2016 at $18 \mathrm{Z}$ at an altitude of $548 \mathrm{~m}$ AGL. The aircraft measurements are shown as circles. Panel (a) shows the wind speed ( $\mathrm{ms}^{-1}$ ) comparison with the WRF-Chem map overlaid with aircraft observations and panel (b) shows the wind direction (degrees) comparison with the WRF-Chem map overlaid with aircraft observations. AGL, above ground level; WRF-Chem, Weather Research and Forecasting Model with Chemistry. 
Table 2

Evaluation of WRF-Chem Using Aircraft Measurements in the Boundary Layer

\begin{tabular}{|c|c|c|c|c|c|c|c|}
\hline \multirow[b]{2}{*}{ Variable } & \multirow[b]{2}{*}{ Units } & \multicolumn{2}{|c|}{ Warm sector } & \multicolumn{2}{|c|}{ Cold sector } & \multicolumn{2}{|c|}{ Cross-frontal difference } \\
\hline & & WRF & Aircraft & WRF & Aircraft & WRF & Aircraft \\
\hline Potential Temperature & K & 313.2 & 311.7 & 305.4 & 307.2 & 7.8 & 4.5 \\
\hline Wind Speed & $\mathrm{ms}^{-1}$ & 6.4 & 5.92 & 12.1 & 10.05 & -5.7 & -4.13 \\
\hline Wind Direction & degrees & 242.9 & 259.96 & 310.75 & 308.71 & -67.85 & -48.75 \\
\hline ABL Depth & m AGL & 836.4 & 770 & 692.6 & 705 & 143.8 & 65 \\
\hline $\mathrm{CO}_{2}$ Mole Fraction & ppm & 409.6 & 406.4 & 395.9 & 394.7 & 13.8 & 11.7 \\
\hline
\end{tabular}

Notes. Cross-frontal differences were calculated as the difference between warm sector and cold sector values. Abbreviations: AGL, above ground level; WRF-Chem, Weather Research and Forecasting Model with Chemistry.

simulated wind speeds were found to be higher than the aircraft observations. Figure $4 \mathrm{~b}$ shows that the simulated wind shift from northwesterly winds in the cold sector to southerly winds in the warm sector at the frontal boundary matches the wind shift measured by the aircraft. In the south-eastern end of the flight track, there is a region of relatively calm winds $\left(<2 \mathrm{~m} \mathrm{~s}^{-1}\right)$ where there is a mismatch in wind direction between model and observations. However, this region is relatively far from the frontal boundary, and wind speeds are low in both the model and the observations.

Figure 3 shows the locations of the aircraft vertical profiles along the flight track where observed virtual potential temperature profiles were used to derive ABL depth and compare to the WRF-Chem diagnosed ABL depth. The WRF-Chem ABL depth was higher in the warm sector and lower in the cold sector. Table 2 summarizes the model-data differences found in different parameters between the warm and cold sectors. The cross-frontal difference was calculated as a difference of the average values from the warm sector (between longitude $-98^{\circ}$ to $-93^{\circ}$ with southerly flow) and the cold sector (between longitude $-99^{\circ}$ to $-96^{\circ}$ with north-easterly flow) from WRF-Chem and the aircraft measurements. Studies conducted using similar WRF-Chem parameters have also reported values of the same order (Díaz-Isaac et al., 2018; Feng et al., 2016).

The response of simulated $\mathrm{CO}_{2}$ mole fractions to the cold front over continental North America can be seen in Figure 5a. The continental scale distribution of $\mathrm{CO}_{2}$ shows large differences in the warm-cold sector mole fraction (between 20-25 ppm) along the frontal boundary. In the cold sector, air with lower $\mathrm{CO}_{2}$ mole-fractions $(<390 \mathrm{ppm})$ is introduced with northwesterly winds coming in from Canada. The warm sector of the front is characterized with southerly flow bringing in air with higher $\mathrm{CO}_{2}$ mole fractions (405-410 ppm). Figure 5b, the high-resolution simulation, shows a "zoomed-in" view of the front and the associated $\mathrm{CO}_{2}$ distribution. An elongated band of air with higher $\mathrm{CO}_{2}$ mole fractions can be seen extending along the frontal boundary. This band has a maximum width of approximately $200 \mathrm{~km}$ and extends from northeastern Kansas $\left(-99^{\circ}\right.$ longitude and $39^{\circ}$ latitude) to northeastern Iowa $\left(-95^{\circ}\right.$ longitude and $44^{\circ}$ latitude) spanning over $600 \mathrm{~km}$. The white box delimits the boundaries of the innermost domain (Figure 5a)

While simulated cross-frontal differences were as high as $25 \mathrm{ppm}$, observed frontal difference, while similar in magnitude, were located northwest of the simulated boundary (between $-98^{\circ}$ to $-97^{\circ}$ longitude). WRF-Chem did simulate the lower $\mathrm{CO}_{2}$ mole fractions observed in the cold sector north of $41^{\circ}$ latitude. The horizontal extent of elevated $\mathrm{CO}_{2}$ mole fractions in the warm sector is narrower in the model compared to the aircraft measurements. This is specifically noticeable in Figure 5c-in WRF-Chem, the elevated concentrations extend from $-96.5^{\circ}$ to $-94^{\circ}$ longitude but in the aircraft measurements extend from $-97.7^{\circ}$ to $-93^{\circ}$ longitude. This could be caused by a small error in the simulated location (Figure $5 \mathrm{~b}$ ) of the high $\mathrm{CO}_{2}$ region found in the model at approximately $-95^{\circ}$ longitude and $39^{\circ}$ latitude.

There is a small region of elevated $\mathrm{CO}_{2}$ mole fractions west of the frontal boundary in the cold sector between $-98^{\circ}$ to $-97^{\circ}$ longitude. This was seen in both aircraft measurements and WRF-Chem. Overall, WRFChem was able to capture the large-scale features of the $\mathrm{CO}_{2}$ distribution at frontal boundary, including the correct sign and approximate amplitude of the cross-frontal difference. Table 2 shows the quantified statistics comparing WRF-Chem and aircraft measurements along the flight track. The distribution of $\mathrm{CO}_{2}$ 
a)

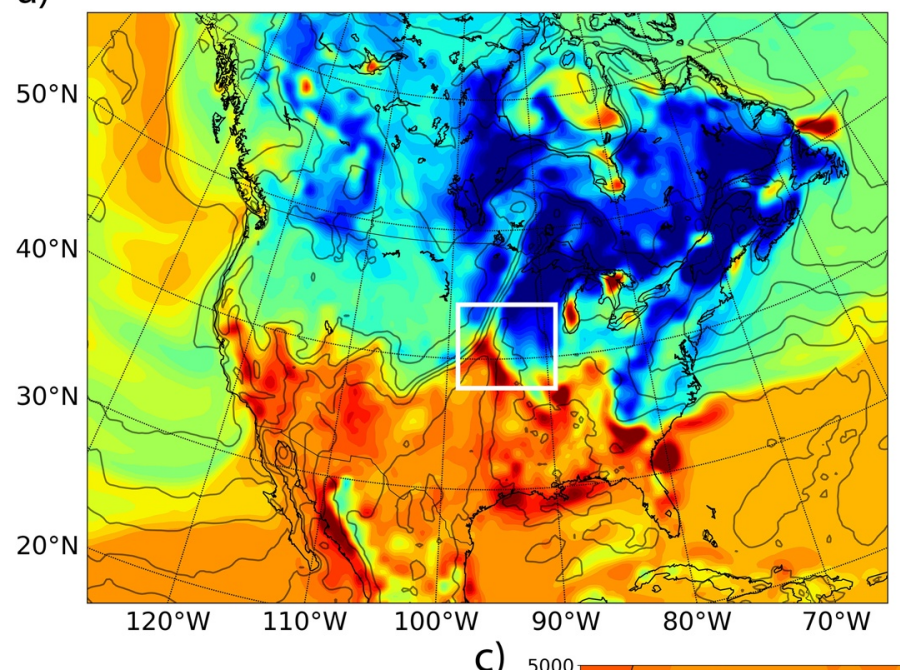

b)

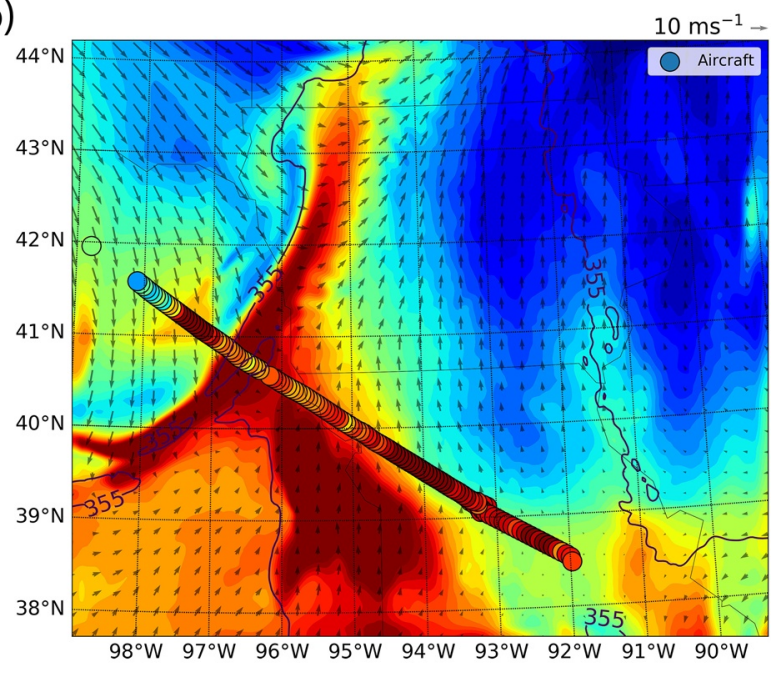

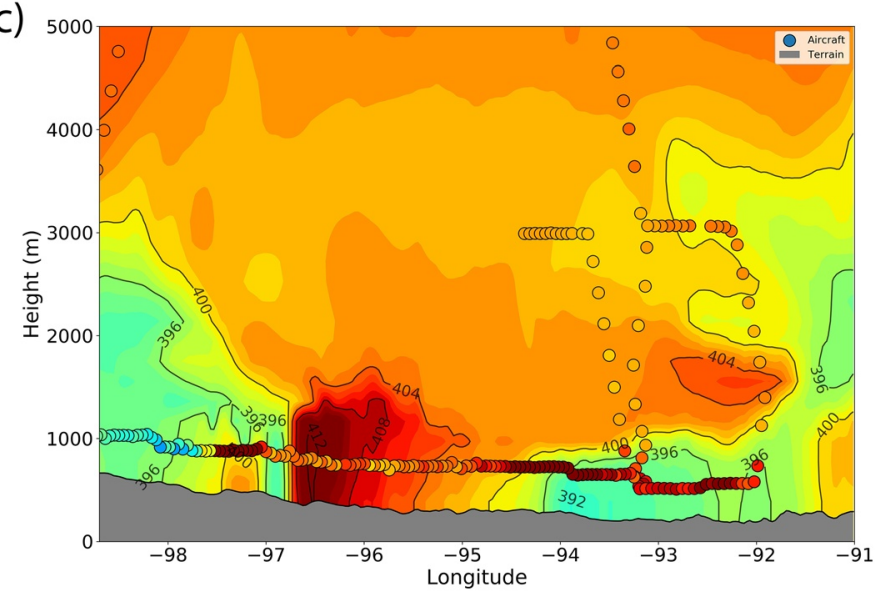

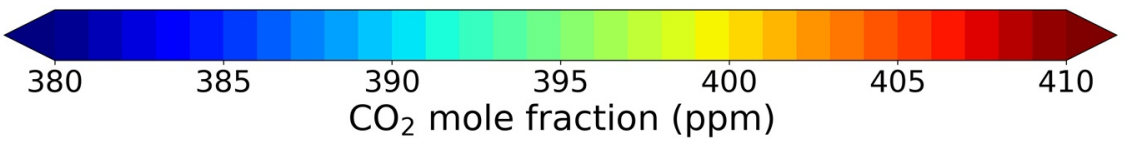

Figure 5. WRF-Chem simulated $\mathrm{CO}_{2}$ mole fractions across continental United States and comparisons to aircraft measurements within the high-resolution ( $3 \mathrm{~km}$ ) domain on August 4th, 2016 at $18 \mathrm{Z}$ at an altitude of $548 \mathrm{~m}$ AGL. The aircraft measurements are shown as circles. Panel (a) shows the horizontal map of $\mathrm{CO}_{2}$ mole fractions from the $27 \mathrm{~km}$ domain highlighting the large scale features in $\mathrm{CO}_{2}$ mole fraction, panel(b) shows simulated $\mathrm{CO}_{2}$ mole fractions from the cloud resolving resolution $3 \mathrm{~km}$ domain overlaid with aircraft observations. Panel (c) shows the vertical cross-section across the frontal boundary highlighting the vertical features as seen by WRF-Chem and the aircraft measurements. AGL, above ground level; WRF-Chem, Weather Research and Forecasting Model with Chemistry.

in the simulated atmosphere is determined by interactions between atmospheric transport and the surface fluxes. The misalignment of the $\mathrm{CO}_{2}$ distribution between WRF-Chem and aircraft can arise from errors either in transport or fluxes and detangling them to quantify the cause is beyond the scope of the current study. Based on the aircraft observations in Figure 5b, it can be seen that the observed frontal boundary was located $100-120 \mathrm{~km}$ to the northeast of the simulated frontal boundary. Also, the southeastern part of the simulation domain has lower $\mathrm{CO}_{2}$ mole fractions than the observations. The aircraft measurements were taken in the boundary layer. The region of mismatch in the southeast (between $-93^{\circ}$ and $-91^{\circ}$ longitude) is likely a timing mismatch due to reduced wind speeds in the region $\left(\sim 0-2 \mathrm{~ms}^{-1}\right)$ as the elevated $\mathrm{CO}_{2}$ mole fractions were not advected in time. On August 4th at 20Z, the simulated $\mathrm{CO}_{2}$ mole fractions in the region between $-93^{\circ}$ and $-92^{\circ}$ longitude are closer to aircraft measured values ( $<2 \mathrm{ppm}$ difference). The cold sector wind speeds were higher in WRF-Chem in comparison to aircraft measurements by $2 \mathrm{~m} \mathrm{~s}^{-1}$ which can lead to the front moving faster in the simulation. In addition to the discrepancies in the wind field in 
a)

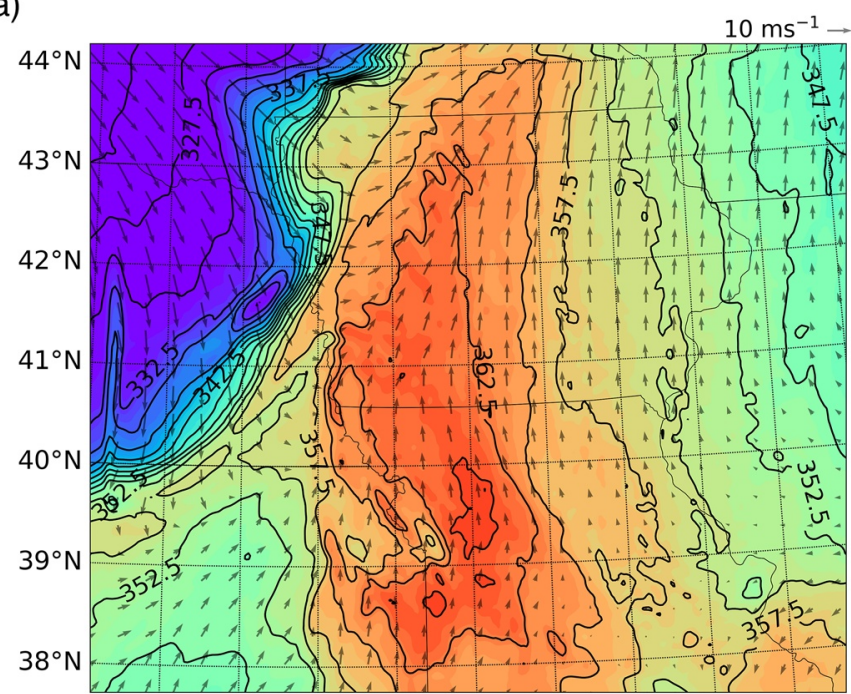

$98^{\circ} \mathrm{W} 97^{\circ} \mathrm{W} 96^{\circ} \mathrm{W} 95^{\circ} \mathrm{W} 94^{\circ} \mathrm{W} 93^{\circ} \mathrm{W} 92^{\circ} \mathrm{W} 91^{\circ} \mathrm{W} 90^{\circ} \mathrm{W}$ b)

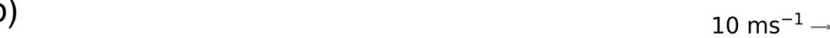

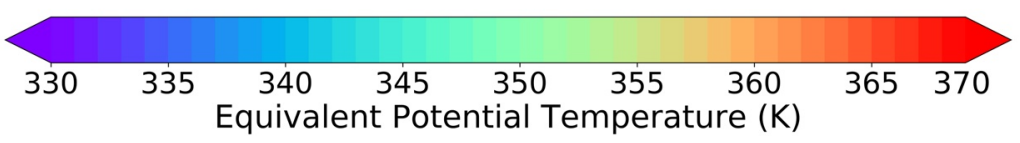

Figure 6. Map of equivalent potential temperature $\left(\theta_{e}\right)$ at an elevation of $548 \mathrm{~m}$ (AGL) at $18 \mathrm{Z}$ on August 4 th as simulated by WRF-Chem. Panel (a) shows

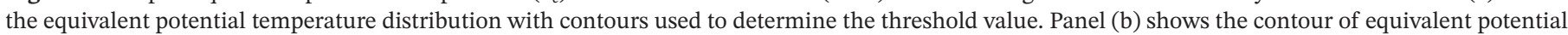
temperature threshold value $\left(\theta_{e}=355 \mathrm{~K}\right)$ highlighting the location of the front. The white line shows the transect used to study features across the frontal

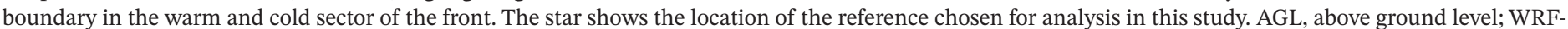
Chem, Weather Research and Forecasting Model with Chemistry.

the warm and cold sector, WRF-Chem also simulated a stagnant air mass in the eastern part of the domain between $-93^{\circ}$ and $-89^{\circ}$ longitude with low $\mathrm{CO}_{2}(<390 \mathrm{ppm})$. The presence of this stagnant air mass was not confirmed using aircraft measurements due to the spatial extent of the flights. The stagnant air mass could also be a cause for the discrepancy in $\mathrm{CO}_{2}$ mole fractions between aircraft measurements and WRF-Chem. The flight was designed to sample the cold-warm frontal difference. The boundary between the southern/ warm sector and northeastern air mass was not obvious. The flight was very close to this boundary but did not cut across it-a preferable strategy for sampling the $\mathrm{CO}_{2}$ structure of the weather system, making our model-data comparison in the warm sector (Figure 5) highly sensitive to the simulated location of this boundary. It appears that the warm sector moves to the northeast more slowly in the simulation than in reality, as the flight track appears to be moving through the higher $\mathrm{CO}_{2}$ warm sector $\mathrm{ABL}$ air.

Even though the $\mathrm{CO}_{2}$ distribution was not exactly represented as measured by the aircraft, WRF-Chem's performance in simulating the large-scale $\mathrm{CO}_{2}$ features during the frontal passage as well as meteorological variability allows it to qualify as a platform to study $\mathrm{CO}_{2}$ transport.

\subsection{Synoptic-Scale Weather and $\mathrm{CO}_{2}$ Distributions on August 4th}

In the current study, WRF-Chem simulation of $\mathrm{CO}_{2}$ distributions during the cold front passage show the presence of a narrow band of elevated mole fractions aligned with frontal boundary.

Figure 6 shows the distribution of equivalent potential temperature $\left(\theta_{e}\right)$ within the innermost simulation domain at an elevation of $548 \mathrm{~m}$ AGL at $18 \mathrm{Z}$ on August 4th. The frontal location was determined by the maximum gradient in $\theta_{e}$ in the innermost high-resolution domain (Pauluis et al., 2008). In Figure 6a, based on the contours of $\theta_{e}$, the cold front extends from the border of Minnesota and South Dakota (located at $44^{\circ}$ longitude and $-95^{\circ}$ longitude) in the north to $40^{\circ}$ latitude and $-99^{\circ}$ longitude at the western edge of the domain. The maximum gradient is located between $-94^{\circ}$ longitude and $-97^{\circ}$ longitude between the $41^{\circ}$ latitude and $42^{\circ}$ latitude. Based on the gradients in $\theta_{e}$ across the domain, we defined the frontal boundary as the contour line corresponding to a $\theta_{e}$ value of $355 \mathrm{~K}$, which is highlighted in Figure $6 \mathrm{~b}$ as the single 
a)

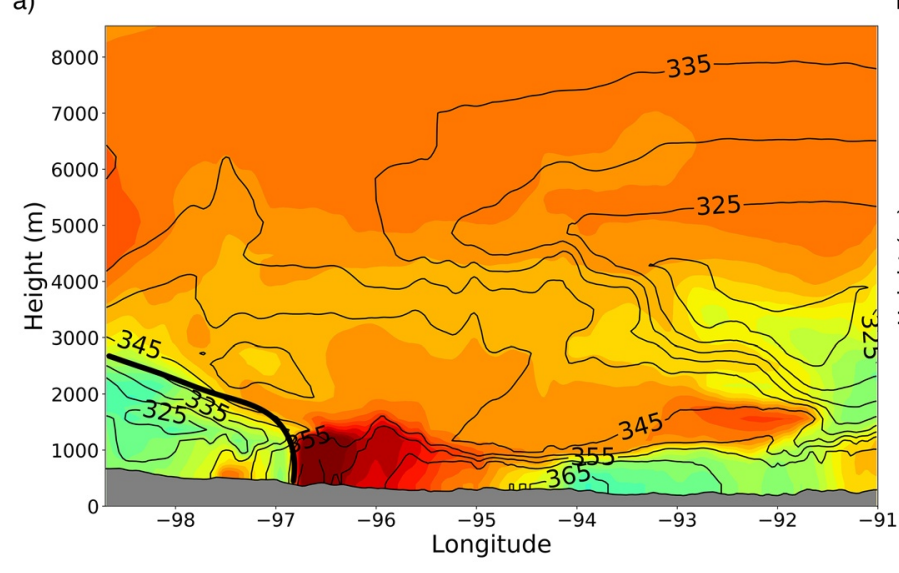

b)

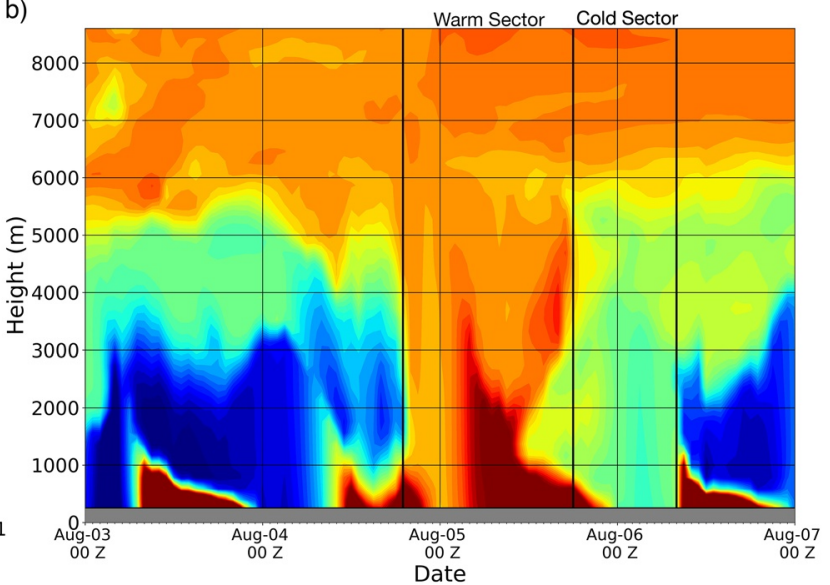

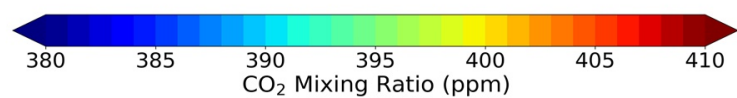

Figure 7. Vertical distribution of $\mathrm{CO}_{2}$ during a cold front passage. (a) Vertical distribution (MSL) of $\mathrm{CO}_{2}$ along the transect (white line in Figure $6 \mathrm{~b}$ ) shown in Figure 6 highlighting the warm and cold sector of the front on August 4th at 18Z. The bold black line shows the slanted structure of the front in the cold sector with lower $\mathrm{CO}_{2}$ mole fractions. (b) Time evolution of $\mathrm{CO}_{2}$ mole fractions over the reference location (white star in Figure $6 \mathrm{~b}$ at $40.9 \mathrm{~N}$ and $96.9 \mathrm{~W}$ ) from August 3rd to August 7th 00Z. The gray regions show the terrain. The vertical black lines in panel (b) show the period of frontal influence from August 4th $18 \mathrm{Z}$ to August 6th 09Z over the reference location. The black vertical lines highlight the period of warm and cold sector passage over the location.

black contour line. In addition to $\theta_{e}$, the locations of the warm and cold sectors of the front are further confirmed by the changing wind directions as seen in Figures $6 \mathrm{a}$ and $6 \mathrm{~b}$. The cold sector has predominantly north-westerly flow covering most of the northwestern region of the domain (between $40^{\circ}$ to $44^{\circ}$ north and $-95^{\circ}$ to $-99^{\circ}$ longitude), while the warm sector can be identified by warmer southerly winds between $37^{\circ}$ to $45^{\circ}$ north and $-92^{\circ}$ to $-98^{\circ}$ longitude.

We select the line extending across the front into the warm and cold sectors and a fixed-point location, referred hereafter as our reference location, where the frontal boundary passes at $18 \mathrm{Z}$ (see Figure 6b) to study the vertical structure of the atmospheric $\mathrm{CO}_{2}$ and its evolution responding to this summertime cold front (Figure 7). Figure 7a shows the impact of the cold front passage on $\mathrm{CO}_{2}$ contribution at a given time across the frontal boundary. In Figure 7a, we see the slanted structure of the front in the cold sector (western region, lower altitudes) identified by air with much lower $\mathrm{CO}_{2}$ mole fractions (380-395 ppm). The $\mathrm{CO}_{2}$ distribution is largely correlated with the alignment of $\theta_{e}$ contours shown as the black contours. In comparison, the warm sector has elevated $\mathrm{CO}_{2}$ mole fractions ( $-94^{\circ}$ to $-95^{\circ}$ longitude) which extend from the surface to approximately $3.5 \mathrm{~km}$ MSL near the frontal boundary-identified as the band of high $\mathrm{CO}_{2}$ along the frontal boundary.

To track the influence of the cold front passage on the local $\mathrm{CO}_{2}$ distribution, a time-series of vertical distribution at the reference location is shown in Figure $7 \mathrm{~b}$. The location experiences elevated $\mathrm{CO}_{2}$ mole fractions between August 4th at $18 \mathrm{Z}$ and August 5 th at $18 \mathrm{Z}$ when the cold front crosses over the location introducing an air mass with lower $\mathrm{CO}_{2}$ mole fractions. The air mass with elevated $\mathrm{CO}_{2}$ concentrations correspond to the warm sector of the front, lasting until August 5th 18Z. The warm sector air mass is followed by the cold sector air mass over the location with lower $\mathrm{CO}_{2}$ mole fractions $(<390 \mathrm{ppm})$. This can be seen in Figure $7 \mathrm{~b}$ between August 6th 00Z and 09Z. The impact of the frontal passage over the location disrupts the repeated diurnal variation features (seen prior to August 4th 18Z). We also see that there are repeated patterns of high and low $\mathrm{CO}_{2}$ mole fractions near the surface-these are caused by the daily cycle of ecosystem fluxes and ABL mixing. Between $18 \mathrm{Z}$ August 4th and 18Z August 5th, when the warm sector air mass passes over the region, there is a period of elevated $\mathrm{CO}_{2}$ mole fractions that is relatively uniform in the distribution, extending above $6 \mathrm{~km}$ MSL. During this period, air mass with pre-existing gradients are advected over the location - these gradients do not represent downward movement of air from higher up in the atmosphere. Beginning at August 5th 18Z, the air mass above the reference location has low $\mathrm{CO}_{2}$ mole fractions $(<390$ ppm). This continues for a few more hours until August 6th 09Z when there is a sharp change (from 410 to 


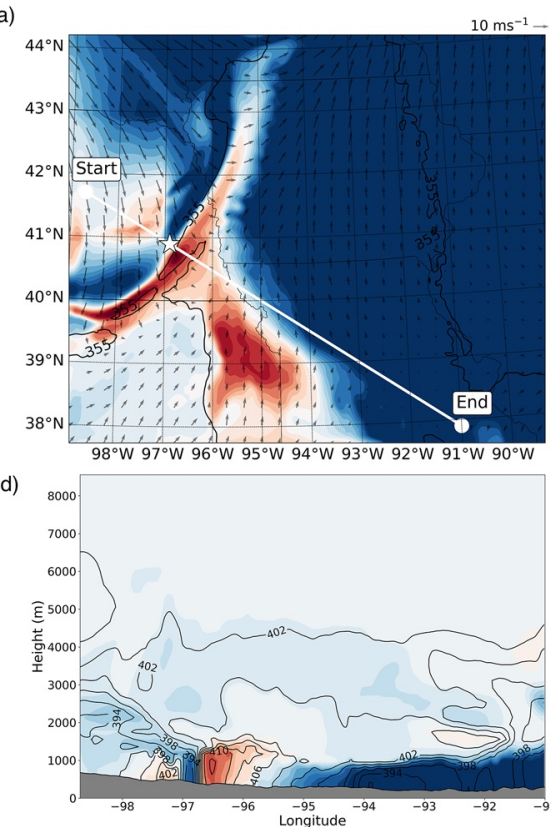

g)

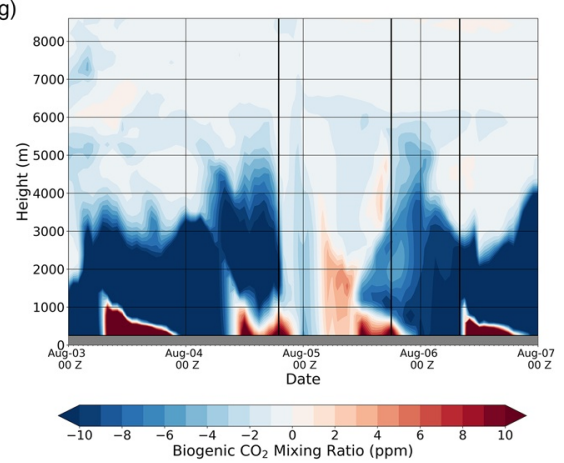

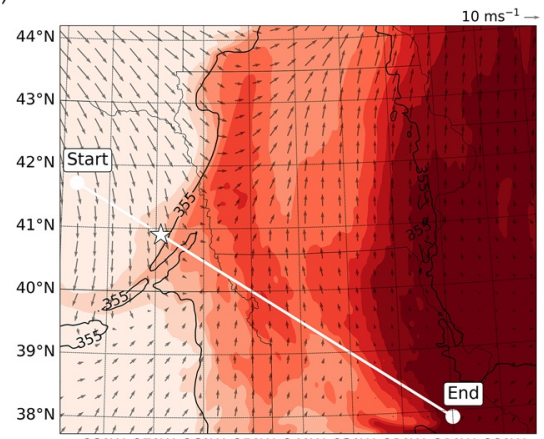

e) 8000
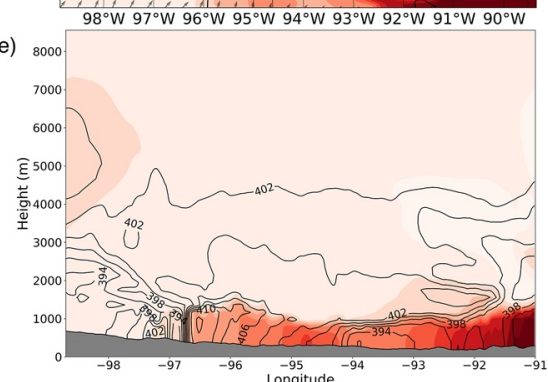

h)

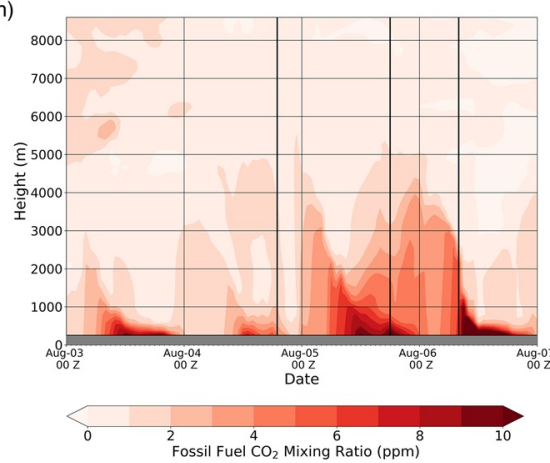

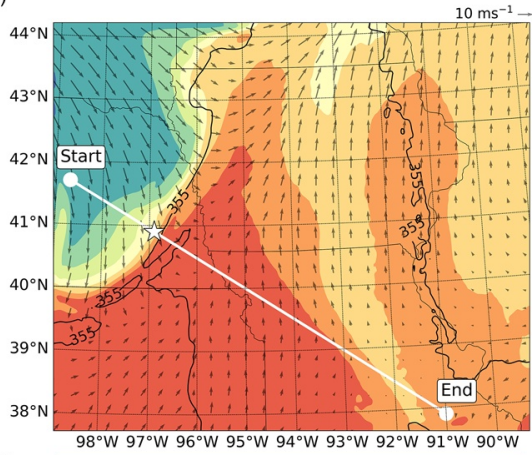
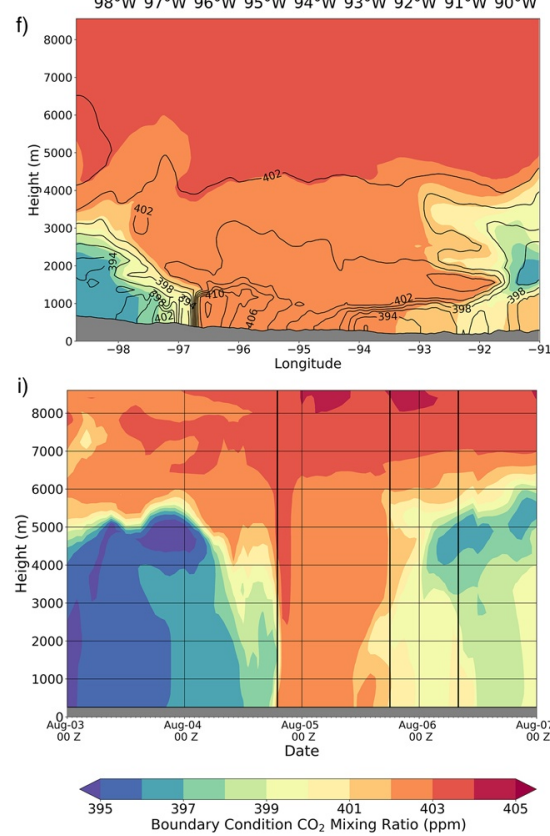

Figure 8. Distribution of $\mathrm{CO}_{2}$ from various sources in WRF-Chem for the August 4th cold front passage. Panels (a-c) show a map of CO from biospheric

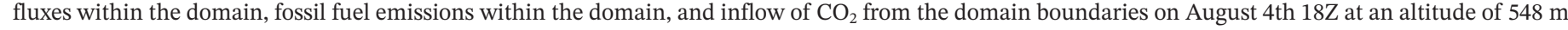

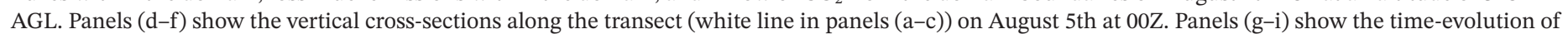

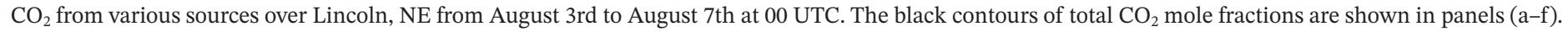
The black vertical lines in panels (g-i) highlight the period of warm and cold sector passage over the location (as seen in Figure $7 \mathrm{~b}$ ).

$392 \mathrm{ppm}$ ) in the vertical distribution of $\mathrm{CO}_{2}$, showing the impact of the post-frontal air mass over the location. The August 6th $09 \mathrm{Z}$ change in the vertical distribution of $\mathrm{CO}_{2}$ corresponds to the pattern seen before the cold front entered the domain. The components of $\mathrm{CO}_{2}$ as well as the transport mechanisms responsible for these features are described in greater detail in Sections 4.3 And 4.4 respectively.

\section{3. $\mathrm{CO}_{2}$ Transport From Various Sources}

We find that $\mathrm{CO}_{2}$ introduced into the domain via boundary conditions along with influences from biogenic and fossil fuel components within the domain determine the distribution of $\mathrm{CO}_{2}$ along the frontal boundary. During this frontal passage, three distinct air masses were present over the region-(i) the cold sector air mass advected in from the northwest with low $\mathrm{CO}_{2}$ mole fractions, (ii) the warm sector air mass with elevated $\mathrm{CO}_{2}$ located in the southwestern region of the domain, and (iii) a stagnant air mass in the northeastern section of the domain with low $\mathrm{CO}_{2}$ mole fractions. The stagnant air mass has high fossil fuel $\mathrm{CO}_{2}$ mole fractions. However, strong negative biogenic signal results in low total $\mathrm{CO}_{2}$ mole fractions. The cross-frontal difference (calculated near the surface at $-97^{\circ}$ longitude on August 4 th at $18 \mathrm{Z}$ in Figure $7 \mathrm{a}$ ) in $\mathrm{CO}_{2}$ mole fractions is similarly influenced by these components. Figure 8 shows the distribution and time-evolution of $\mathrm{CO}_{2}$ mole fractions for each separate component from different perspectives. Based on 
the horizontal maps, at $18 \mathrm{Z}$ on August 4th, strong negative biogenic $\mathrm{CO}_{2}$ (approximately -10 ppm) between $-99^{\circ}$ and $-95^{\circ}$ longitude and $40^{\circ}$ and $44^{\circ}$ latitude are co-located with the cold sector air mass with low $\mathrm{CO}_{2}$ mole fractions as seen previously in Figure $7 \mathrm{~b}$. In the warm sector (between $-96^{\circ}$ and $-94^{\circ}$ longitude and $41^{\circ}$ and $39^{\circ}$ latitude), biogenic fluxes have strong positive magnitudes ( $>8 \mathrm{ppm}$ ) and are aligned with the air mass with elevated $\mathrm{CO}_{2}$ mole fractions in Figure 7a. Additionally, along the frontal boundary there is a sharp change in biogenic $\mathrm{CO}_{2}$ from -10 to $10 \mathrm{ppm}$ near the reference location (shown by the star in Figure $8 \mathrm{a}$ ). Figure $8 \mathrm{~b}$ shows fossil fuel fluxes have elevated mole fraction in the eastern half (between $-92^{\circ}$ and $-90^{\circ}$ longitude) of the domain. The presence of stronger negative transported biogenic signal over the same region cancels out the impact of the elevated fossil fuel mole fractions. The frontal difference is visible in the horizontal map of boundary inflow $\mathrm{CO}_{2}$. However the magnitude of the difference is lower (2-3 ppm) when compared to the total $\mathrm{CO}_{2}$ distribution (20-25 ppm). Biogenic $\mathrm{CO}_{2}$ shows a frontal difference of 20 ppm while the fossil fuel fluxes show a frontal difference of $4 \mathrm{ppm}$. These features are further discussed and differentiated by Pal et al. (2020).

Vertical features in the cross-frontal difference between $\mathrm{CO}_{2}$ mole fractions is shown in Figure 8 (panels d-e). The slanted vertical structure of the cold front seen in Figure 7a is highly correlated with boundary condition $\mathrm{CO}_{2}$ mole fractions. The cross-frontal $\mathrm{CO}_{2}$ difference caused by boundary conditions was around $5 \mathrm{ppm}$ near the surface. The boundary inflow does not modulate the elevated band of $\mathrm{CO}_{2}$ along the frontal boundary. The narrow band of elevated $\mathrm{CO}_{2}(2-6 \mathrm{ppm}$ increase) is located near the frontal boundary from the surface extending to $2 \mathrm{~km} \mathrm{MSL}$, and between $-97^{\circ}$ and $-96^{\circ}$ longitude. This band of elevated $\mathrm{CO}_{2}$, as well as the relatively lower $(\sim 392 \mathrm{ppm})$ near surface $\mathrm{CO}_{2}$ mole fractions between $-95^{\circ}$ and $-91^{\circ}$ longitude are primarily influenced by biogenic $\mathrm{CO}_{2}$ mole fractions due to the changes in biogenic $\mathrm{CO}_{2}$. In Figure 8e, we see that fossil fuel has a positive contribution (2-4 ppm) near the frontal boundary (between $-97^{\circ}$ and $-91^{\circ}$ longitude), and that fossil $\mathrm{CO}_{2}$ emissions are counteracted by the co-located strong biogenic $\mathrm{CO}_{2}$ drawdown $(-10 \mathrm{ppm})$ in the lower atmosphere-further confirming that the elevated $\mathrm{CO}_{2}$ mole fractions from fossil fuels were not a major driver of frontal $\mathrm{CO}_{2}$ anomalies during the August 4th cold front passage.

The analysis on the temporal evolution of various components of $\mathrm{CO}_{2}$ seen in Figure 8, panels (g-i), shows that during the period of frontal passage, there are changes in the near surface $\mathrm{CO}_{2}$ mole fractions driven by biogenic sources, followed by fossil fuel sources acting on $\mathrm{CO}_{2}$ advected in by boundary inflow. Variability in the vertical profile of biogenic $\mathrm{CO}_{2}$ mole fractions are shown in Figure 8g. Diurnal net ecosystem exchange and deep ABL mixing can be seen as the repeating low $\mathrm{CO}_{2}$ mole fractions extending into the lower troposphere, coupled with nocturnal respiration causing high $\mathrm{CO}_{2}$ mole fractions near the surface. This pattern is disrupted on August 4th at $18 \mathrm{Z}$, as elevated $\mathrm{CO}_{2}$ mole fractions are present in the atmosphere above the reference location. The difference in near surface $\mathrm{CO}_{2}$ mole fractions between the pre-frontal and frontal periods is $25 \mathrm{ppm}$ as seen in Figure $7 \mathrm{~b}$. The elevated $\mathrm{CO}_{2}$ mole fractions persist over the region for $30 \mathrm{~h}$ followed by a shorter period of depleted $\mathrm{CO}_{2}$ mole fractions. The diurnal pattern resumes around $09 \mathrm{Z}$ on August 6th. This disruption to the diurnal pattern and the consequent change in the vertical distribution of $\mathrm{CO}_{2}$ over the location is attributed to the cold front passage. From the fossil fuel mole fractions shown in Figure 8h, the only significant positive influence (between 4 to $6 \mathrm{ppm}$ ) in mole fractions exists between August 5th $00 \mathrm{Z}$ to August 6th $09 \mathrm{Z}$, contributing 7-10 ppm/hr to the total near surface change in $\mathrm{CO}_{2} \mathrm{~mole}$ fractions. These positive modulations in fossil fuel $\mathrm{CO}_{2}$ mole fractions reduce sharply toward the end of the frontal passage period after August 6th 09Z. The biogenic $\mathrm{CO}_{2}$ mole fractions are responsible for the diurnal patterns (Figure $8 \mathrm{~g}$ ) as they represent the uptake of $\mathrm{CO}_{2}$ by photosynthesis during the day and accumulation due to respiration at night. On August 5th at $04 \mathrm{Z}$ we see that biogenic $\mathrm{CO}_{2}$ mole fractions shift from -4 to 4 ppm, coinciding with the warm sector air mass passing over the location.

The spatial distribution of biogenic $\mathrm{CO}_{2}$ mole fractions in the atmosphere is not a simple reflection of surface fluxes. The sharp boundaries shown in Figure $8 \mathrm{a}$ are driven by weather system boundaries that bring together larger-scale, regional differences in both fluxes and continental boundary conditions. Figure S3 in the supporting information section highlights the variability in biogenic and fossil fuel surface fluxes over a 30-h period from August 4th 00Z to August 5th 06Z during the cold front passage over the domain. The spatial boundaries are co-located with three-distinct air mass regions-(i) the cold sector from the west, (ii) warm sector air from the Gulf of Mexico in the south, and (iii) a stagnant air mass located ahead of the 
warm air inflow in the northeast of the domain (D02). These air mass boundaries are created by the cold front passage over the region.

The cold sector air has nearly no fossil $\mathrm{CO}_{2}$, moderate biogenic $\mathrm{CO}_{2}$ depletion from northern biomes, and relatively low boundary $\mathrm{CO}_{2}$, also from northern latitudes. The western regions immediately upwind of the cold front exhibit relatively small biogenic $\mathrm{CO}_{2}$ fluxes. The southern warm sector air includes modest fossil $\mathrm{CO}_{2}$, relatively higher boundary condition $\mathrm{CO}_{2}$ due to inflow from the Gulf of Mexico, and very little biogenic $\mathrm{CO}_{2}$ due to a small fetch over southern US biomes, exhibiting a large daily cycle of $\mathrm{CO}_{2}$ fluxes which nearly balance over the course of a day. The northeastern air includes modest fossil $\mathrm{CO}_{2}$, relatively low boundary $\mathrm{CO}_{2}$ characteristic of a more northern air mass origin, and strong biogenic $\mathrm{CO}_{2}$ uptake from upper Midwestern agriculture. These regional $\mathrm{CO}_{2}$ flux differences lead to the different biogenic $\mathrm{CO}_{2}$ mole fractions across the study domain, but the flux boundaries are broad and diffuse. The sharp differences found at the front are due to the focusing of these air mass boundaries by passage of the front. The strong daily cycle of biogenic $\mathrm{CO}_{2}$ fluxes in the immediate area of the front leads to strong daily fluctuations in the mesoscale frontal $\mathrm{CO}_{2}$ differences.

We find that boundary inflow $\mathrm{CO}_{2}$ is responsible for roughly $20 \%$ of the pre-frontal and frontal near surface difference in $\mathrm{CO}_{2}$ at this location. During the frontal passage, boundary $\mathrm{CO}_{2}$ is relatively homogeneous in the vertical distribution, with mole fractions similar to upper free tropospheric values throughout the col-

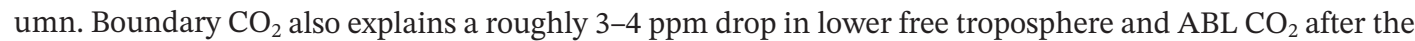
frontal passage. The primary driver of the frontal difference is biogenic $\mathrm{CO}_{2}$, as it explains about $60 \%$ of the total change in $\mathrm{CO}_{2}$ within the $\mathrm{ABL}$ between pre-frontal and frontal conditions. Horizontal maps of total $\mathrm{CO}_{2}$ mole fractions as well as biogenic, fossil fuel and boundary inflow components from August 4th $00 \mathrm{Z}$ to August 5th $06 \mathrm{Z}$ at 6-h intervals are presented in the supporting information section as Figure S2. The maps highlight the changes in cross frontal $\mathrm{CO}_{2}$ distribution as well as the narrow band of elevated $\mathrm{CO}_{2}$ as the cold front passes through the domain. The impact of biogenic $\mathrm{CO}_{2}$ signals on the narrow band of elevated $\mathrm{CO}_{2}$ along the frontal boundary can clearly be seen on the maps. Biogenic fluxes of $\mathrm{CO}_{2}$ are uncertain, and the simulated magnitude of the change in biogenic $\mathrm{CO}_{2}$ mole fractions are thus also uncertain. However, the general consistency of our results with aircraft observations (Table 2; Figure 5), and confidence in the broad-scale continental and daily pattern of summer biogenic $\mathrm{CO}_{2}$ fluxes lends confidence in the signs and approximate magnitudes of these simulated patterns. An examination of the impact of flux uncertainty is a worth topic for future study.

We further explore the components of $\mathrm{CO}_{2}$ within WRF-Chem with a footprint analysis (Figures 9c and 9d) showing the air mass history across the frontal gradient. Simulated particles were released at $300 \mathrm{~m}$ above Lincoln, NE on August 4th, 20Z (during frontal crossing) and August 5th, 03Z (post-frontal crossing). These particles were tracked backwards for 5 days using a Lagrangian particle dispersion model (Uliasz, 1994) and their interactions with the surface were summed to create an influence function of the air measured above Lincoln before and after the frontal crossing. From Figure 9c, we see that the cold sector ABL air at this time and location originated in the southwestern Canada, while the warm sector (Figure 9d) air came from the south-central region to the south. The biogenic surface fluxes in Figure 9a are averaged over 5 days and do not quantitatively reflect the impact of the diel variations in fluxes. Studies have shown that meridional gradients in $\mathrm{CO}_{2}$ mole fractions exist over periods longer than 5 days (Keppel-Aleks et al., 2011). Qualitatively, there is not a large difference in the net biological fluxes in these two upwind areas; neither back trajectory comes from the region of strong net uptake (approximately $-9,000 \mathrm{~mol} \mathrm{~km}^{-2} \mathrm{hour}^{-1}$ ) to the north and northeast of the flight path. This result is likely to be specific to this frontal case. Since fossil fuel fluxes do not have as strong a diel variability as do biogenic fluxes, the 5-day average better represents the distribution and magnitude of fluxes.

\subsection{Mechanism of $\mathrm{CO}_{2}$ Transport Along the Frontal Boundary}

Horizontal and vertical advection are the primary transport terms that drive the distribution of $\mathrm{CO}_{2}$ at the frontal boundary. We compare the three terms driving $\mathrm{CO}_{2}$ mole fraction gradients in both vertical and horizontal directions (cf. Section 2.5) as described in Equation 2, which are (i) horizontal advection, (ii) vertical advection, and (iii) vertical diffusion. Figure 10 shows the transport terms along the transect shown in Figure 6b. Since this figure represents a snapshot in time, the sign of the transport term does not reflect 
a)

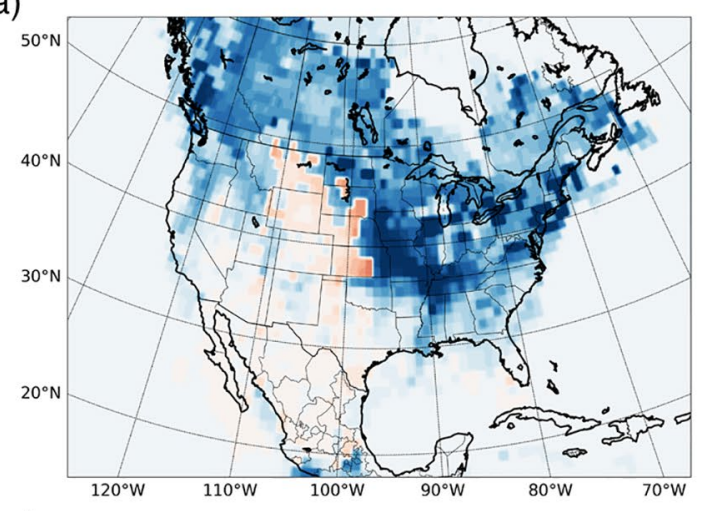

c)

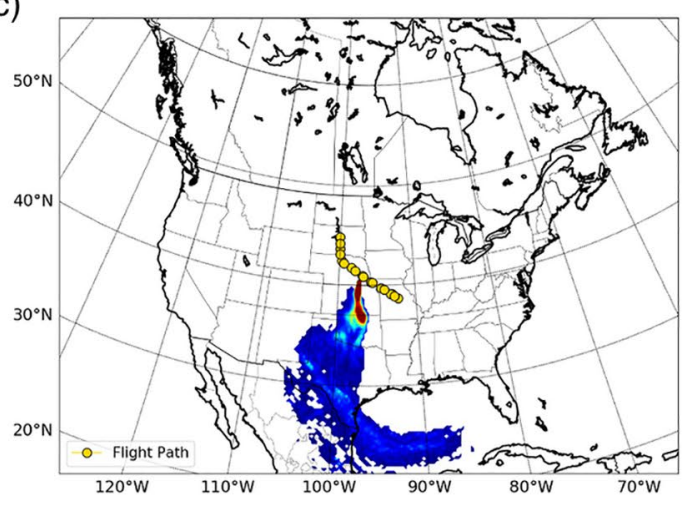

b)

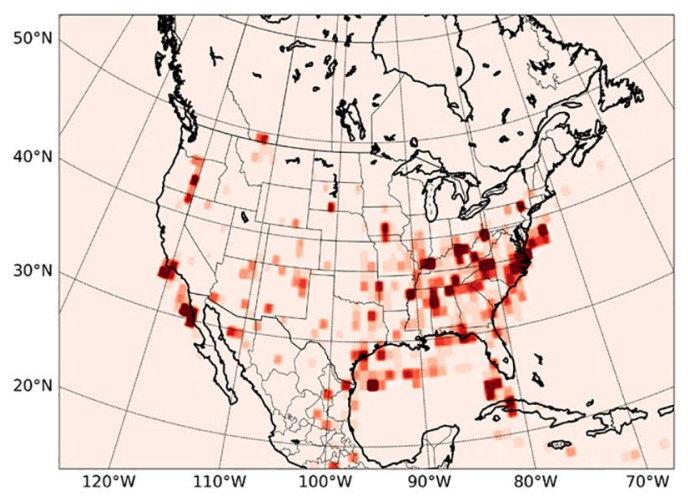

d)

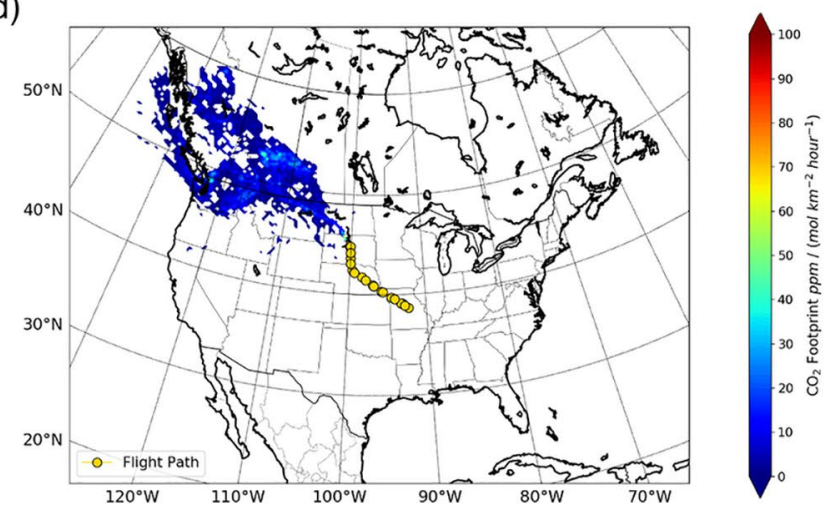

Figure 9. Footprint analysis of air mass along the frontal boundary showing the surface fluxes from CT-NRT.v2017 and regions of influence. Panel(a) has biogenic $\mathrm{CO}_{2}$ surface fluxes and panel (b) shows fossil fuel $\mathrm{CO}_{2}$ surface fluxes. The surface flux maps have been averaged over 5 days. Panel (c) shows the air mass history for the warm air mass ahead of the front and panel (d) shows the air mass history for the cold air mass behind the front. The flight path is shows as yellow circles.

its influence for the period of frontal passage. Overall, horizontal advection is strongest near the frontal boundary and a positive influence in the warm sector. The magnitude of horizontal advection is greatest at the frontal boundary, where the $\mathrm{CO}_{2}$ mole fraction gradient is the strongest. As seen in Figure 10a, horizontal advection has a high magnitude $(\sim 10 \mathrm{ppm} / \mathrm{hr})$ in the ABL at the sector of the frontal boundary (between $-97^{\circ}$ and $-96^{\circ}$ longitude). Near surface values of horizontal advection have positive values in the warm sector and negative values of similar magnitude in the cold sector. Alternating negative and positive values can be interpreted as transport of $\mathrm{CO}_{2}$ from a depleted region followed by an elevated $\mathrm{CO}_{2}$ region due to changes in the direction of the $\mathrm{CO}_{2}$ flow as the cold front propagates. Further into the warm sector (Figure $6 \mathrm{~b}$ ) of the front, there is a region of accumulation caused by horizontal advection between $-96^{\circ}$ and $-94^{\circ}$ longitude. However, the magnitudes are not as high as those near the frontal boundary.

The influence of vertical advection on the distribution of $\mathrm{CO}_{2}$ across the front is generally restricted to the region close to the frontal boundary (between $-97^{\circ}$ and $-95^{\circ}$ longitude) as seen in Figure 10b. However, unlike horizontal advection, the magnitude of vertical advection is significantly lower than horizontal advection ( $2 \mathrm{ppm} / \mathrm{hr}$ compared to $10 \mathrm{ppm} / \mathrm{hr}$ ) as seen in Figure 10b. While vertical advection has a very low magnitude in Figure 10b, horizontal maps of vertical advection at multiple levels show the significant transport just above the ABL. These maps are shown as Figure S1 in the supporting information section.

Vertical diffusion has a significantly smaller magnitude than the advection terms-contributing less than $2 \times 10^{-3} \mathrm{ppm} / \mathrm{hr}$ to the total $\mathrm{CO}_{2}$ transport during the frontal passage period. Thus, for this cold front passage, horizontal advection is the primary transport term active near the frontal boundary and in the warm sector as well. The magnitude of the transport terms are greatest in the ABL, and drop to smaller values (around 1-2 ppm/hr) in the free troposphere. Based on the cross-section shown in Figure 10, horizontal 

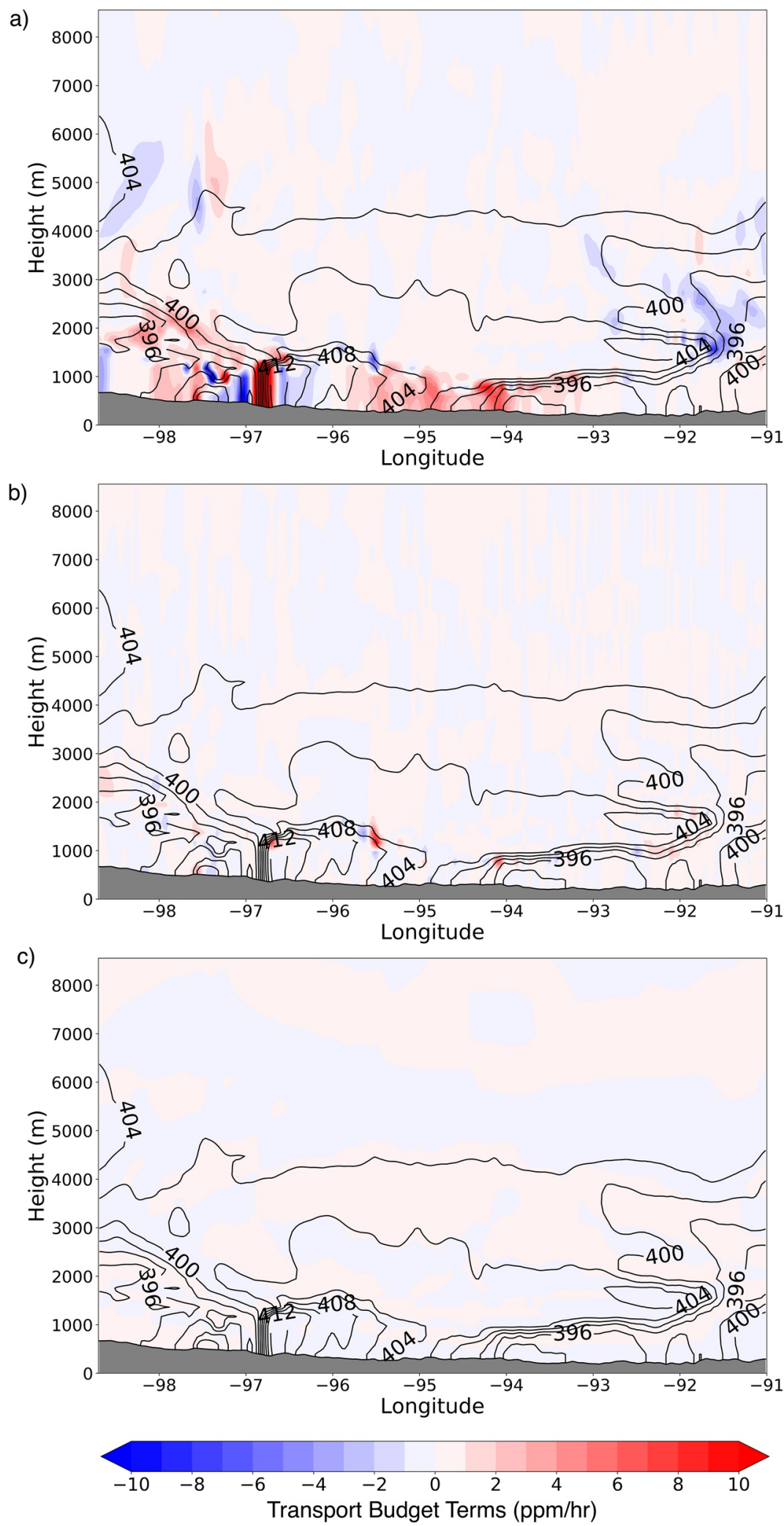

Figure 10. Transport processes impacting $\mathrm{CO}_{2}$ distribution across the frontal boundary on August 4th at $18 \mathrm{Z}$ along the transect shown in Figure 6b. The colored contours show the transport terms while the black contour lines represent the corresponding $\mathrm{CO}_{2}$ mole fractions. Panel (a) shows horizontal advection, panel (b) shows vertical advection and panel (c) shows vertical diffusion. 


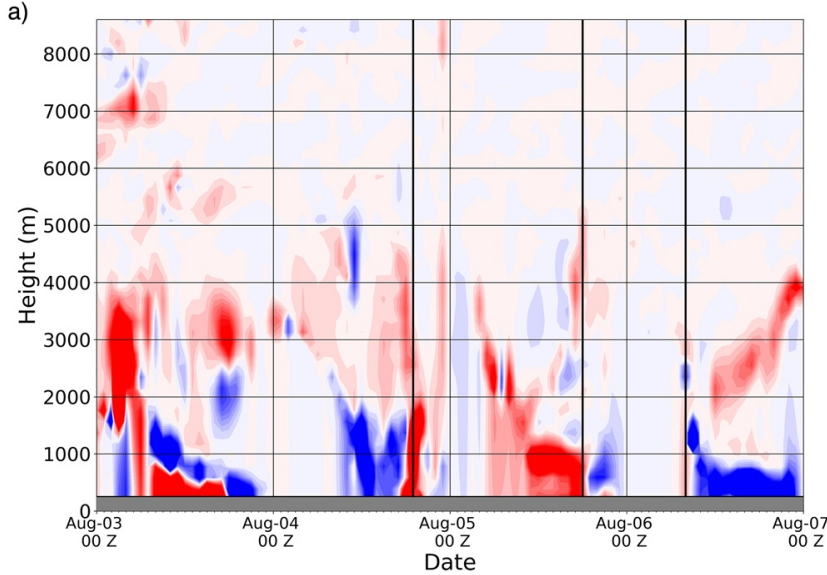

b)
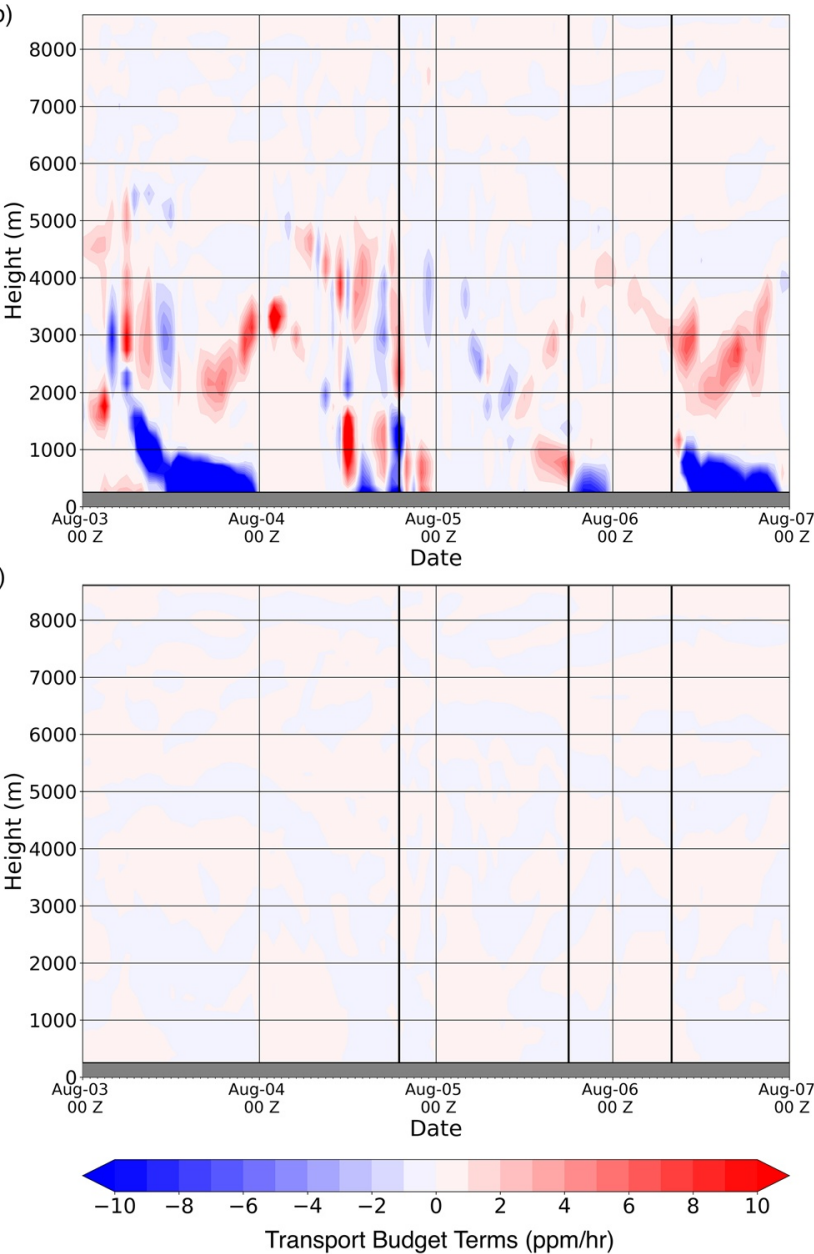

Figure 11. Evolutions of transport terms impacting $\mathrm{CO}_{2}$ distribution across the frontal boundary from August 3rd to August 7th at 00Z over the reference location in Nebraska as shown in Figure 6b. The vertical black lines show the period of frontal influence from August 4th 18Z to August 6th 09Z over the reference location. Panel (a) shows horizontal advection, panel (b) shows vertical advection and panel (c) shows vertical diffusion. The black vertical lines highlight the period of warm and cold sector passage over the location (as seen in Figure 7b). advection accounts for most of the total $\mathrm{CO}_{2}$ transport while vertical advection contributes to $\mathrm{CO}_{2}$ transport especially near the top of the ABL.

Evolution of the vertical distribution of transport budget terms over a location shows that the terms have the greatest magnitude at the beginning of frontal influence and at the frontal boundary between the warm and cold sectors. In Figure 11a, the vertical distribution of horizontal advection over the reference location is shown from August 3rd to August 7th 00Z. At the start of the frontal influence around August 4th 18Z, there is a sharp increase in the magnitude of horizontal advection with negative influence in the boundary layer $(-10 \mathrm{ppm} / \mathrm{hr})$. This increase in magnitude is restricted to the ABL. Between 2 to $3 \mathrm{~km} \mathrm{MSL}$, there is a positive ( $2 \mathrm{ppm} / \mathrm{hr}$ ) region. The abrupt change in signs near August 4th $18 \mathrm{Z}$ can be attributed to the change in air masses due to introduction of the warm sector (Figure 11a) over the region. Simultaneously, the distribution of vertical advection is shown in Figure 11b. Unlike horizontal advection, vertical advection does not show ( $>8 \mathrm{ppm} / \mathrm{hr}$ ) near surface influences during the pre-frontal period (apart from the nocturnal buildup). During the initial period of frontal influence, vertical advection has reduced $(<4$ $\mathrm{ppm} / \mathrm{hr}$ ) influence under $1 \mathrm{~km}$ MSL. The distribution above $1 \mathrm{~km}$ MSL is similar to horizontal advection with the opposite sign. The frontal boundary separating the warm and cold sectors passes over the location around August 5th 18Z.

Vertical advection has significant magnitude in the ABL during the nocturnal buildup period and when the frontal influence is present over the location between August 4th $18 \mathrm{Z}$ and August 6th $00 \mathrm{Z}$ as seen in Figure 11b. From Figures $11 \mathrm{a}$ and $11 \mathrm{~b}$ it can be seen that during the warm sector period from August 4th 18Z to August 5th 00Z, there is an overlap of vertical and horizontal advection in the ABL as well as the lower free troposphere. Within the ABL, vertical advection has the opposing impact compared to horizontal advection. Dynamically speaking, vertical advection lifts air mass with elevated $\mathrm{CO}_{2}$ to regions with lower $\mathrm{CO}_{2}$ mole fractions, thereby causing accumulation in the vertical distribution of $\mathrm{CO}_{2}$. Horizontal advection carries this air mass with increased $\mathrm{CO}_{2}$ mole fractions into air with lower mole fractions and depletes the combined $\mathrm{CO}_{2}$ mole fractions. As the frontal boundary passes over the location (between August 5th 18Z and August 6th 18Z), based on Figures 10 and 11, it can be seen that majority of the boundary layer $\mathrm{CO}_{2}$ transport in the cold sector of the front is driven by horizontal transport.

Vertical diffusion does not show any transport in the same order of magnitude as the advection terms throughout the period from August 3rd $00 \mathrm{Z}$ to August 7th 00Z. From Figure 11c we see that there is no change in magnitude of the vertical diffusion term throughout the period of frontal influence over the location.

In summary, horizontal advection is the primary transport mechanism during the frontal period. For horizontal advection and vertical advection, the impact during frontal passages differ from non-frontal periods. In comparison, vertical diffusion is not affected by the cold front passage. Based on the sign of the terms as well the region and period of influence, horizontal and vertical advection show a coupled transport impact during the warm sector of the frontal passage period. 


\section{Discussion and Conclusions}

In this study, we presented findings from a cloud resolving resolution simulation of a cold front passage on August 4th over Lincoln, Nebraska in the Mid-West region of United States. The performance of the WRF-Chem setup used was evaluated using aircraft measurements from the ACT-America 2016 campaign. In order to understand the changes in atmospheric $\mathrm{CO}_{2}$ mole fractions during the cold front passage, we showed the contribution of biogenic and fossil fuel sources along with large scale inflow from the domain boundaries. Using a modified form of a $\mathrm{CO}_{2}$ budget equation (Bakwin et al., 2004; Parazoo et al., 2008), we quantified the interaction of horizontal advection, vertical advection, and vertical diffusion with $\mathrm{CO}_{2}$ mole fractions during the cold front passage.

Focusing on a single cold front passage, we were able to simulate the changes in the distribution of $\mathrm{CO}_{2}$ on both sides of the cold front. We found that the cold sector of the front had an air mass with lower $\mathrm{CO}_{2}$ mole fractions $(<400 \mathrm{ppm})$ compared to the warm sector $(>405 \mathrm{ppm})$. The presence of horizontal gradients in $\mathrm{CO}_{2}$ mole fractions across the frontal boundary was consistent with previous studies (Hurwitz et al., 2004; Wang et al., 2007). In addition to the large scale difference in $\mathrm{CO}_{2}$ mole fractions across the frontal boundary, we also found the presence of a narrow band of elevated $\mathrm{CO}_{2}$ mole fractions located along the frontal boundary extending into the warm sector. This air mass had the highest $\mathrm{CO}_{2}$ mole fractions $(>410 \mathrm{ppm})$ and was distinct from the warm sector air mass surrounding it. The simulated $\mathrm{CO}_{2}$ enhancement had a similar magnitude to aircraft measurements and the location of the enhanced $\mathrm{CO}_{2}$ region was located further to the northwest in aircraft measurements. While previous studies have linked observed increases in $\mathrm{CO}_{2}$ mole fractions associated with a cold front passage to anomalies created due to wind flow deformation and shear (Lee et al., 2012), in this study, we have presented the horizontal and vertical extent of this feature. Through the decomposition of $\mathrm{CO}_{2}$ mole fractions into its source regions, we found that the cold sector air mass originated over southwestern Canada, while the warm sector air mass originated over the Gulf of Mexico. The changes in $\mathrm{CO}_{2}$ mole fractions during the frontal passage can be attributed to a large scale difference in $\mathrm{CO}_{2}$ mole fractions between the warm and cold sector air masses along with the elevated $\mathrm{CO}_{2}$ mole fractions along the frontal boundary. By decomposing atmospheric $\mathrm{CO}_{2}$ mole fractions into source based components, we found that the large scale gradient was represented in the boundary inflow as well as the local (within domain) biogenic $\mathrm{CO}_{2}$ component. The elevated $\mathrm{CO}_{2}$ mole fractions along the frontal boundary were driven by biogenic $\mathrm{CO}_{2}$ mole fractions from within the domain. Similar to Chan et al. (2004), we also found that the interaction of $\mathrm{CO}_{2}$ mole fractions from biogenic sources with horizontal and vertical advection is the primary driver of $\mathrm{CO}_{2}$ gradients during the cold front passage. Using the the $\mathrm{CO}_{2}$ budget equation (Bakwin et al., 2004; Parazoo et al., 2008), we found that horizontal advection is the dominant transport mechanism during the cold front passage, while vertical advection plays an important role near the frontal boundary in the warm sector. We have shown a detailed analysis of transport processes for a single frontal passage case study using a high resolution numerical model capable of resolving most of the vertical transport near the frontal boundary. We found that during the cold front passage, gradients in $\mathrm{CO}_{2}$ mole fractions were advected into the region through the boundary inflow component as also seen in Geels et al. (2004). These boundary inflow gradients extended from the surface to 5,000 m AGL.

We highlight the main conclusions from our study on $\mathrm{CO}_{2}$ distribution, origins, and transport along a frontal boundary for the August 4th cold front passage as follows:

1. Using high-resolution WRF-Chem simulations, we showed an elongated band of elevated ( $>410 \mathrm{ppm})$ $\mathrm{CO}_{2}$ mole fractions along the frontal boundary. This band was captured in aircraft measurements as a part of the ACT-America flight campaign as well (Davis et al., 2018; Pal et al., 2020). The role of this feature in determining the continental scale transport of $\mathrm{CO}_{2}$ remains unclear and is worthy of additional study

2. We found that $\mathrm{CO}_{2}$ introduced into our domain by horizontal advection as boundary inflow had horizontal and vertical gradients along the frontal boundary. These gradients were weaker than those observed near the frontal boundary. Our study quantitatively showed that combining local biogenic and fossil fuel $\mathrm{CO}_{2}$ mole fractions to the boundary $\mathrm{CO}_{2}$ resulted in gradients similar to observations

3. At a cloud-resolving resolution of $3 \mathrm{~km}$, our study was able to capture the vertical transport of $\mathrm{CO}_{2}$ at the frontal boundary in greater detail compared to previous studies with coarser resolutions-this improvement in representation of physical processes due to increase in resolution has previously been shown 
in air quality and convective precipitation studies (Ekström \& Gilleland, 2017; Li et al., 2019). Near the frontal boundary in the warm sector, where the gradients in $\mathrm{CO}_{2}$ are strongest, horizontal and vertical advection have comparable magnitudes

4. We also showed fractional contributions to cross frontal $\mathrm{CO}_{2}$ differences in the boundary layer and free troposphere from each component (biogenic, fossil fuel, and boundary inflow). For the August 4th cold front passage, biogenic $\mathrm{CO}_{2}$ was the primary driver of the narrow band of elevated $\mathrm{CO}_{2}$ along the frontal boundary. Boundary inflow along with biogenic $\mathrm{CO}_{2}$ were the major contributors to the cross frontal $\mathrm{CO}_{2}$ difference. The evolution of the narrow band and the cross frontal difference was shown over multiple days as the cold front passed over the region-highlighting the distinct impact of frontal passage on local CO mole fractions

This study provides new insight into the causes of spatial patterns in atmospheric $\mathrm{CO}_{2}$ and the mechanisms for transport of $\mathrm{CO}_{2}$ associated with frontal passages. The new understanding of the causes of spatial patterns in $\mathrm{CO}_{2}$ aids in the interpretation of atmospheric $\mathrm{CO}_{2}$ mole fraction measurements used to infer biogenic $\mathrm{CO}_{2}$ fluxes via inversion systems. We found that frontal systems contain powerful insight into upwind biogenic $\mathrm{CO}_{2}$ fluxes from large portions of the continent. Resolving these features will enable inversion systems to use the data to constrain these upwind fluxes. Our high-resolution simulation also begins to quantify the importance of vertical advection at the frontal boundary. This transport is important to all inversion systems since this vertical mixing redistributes local fluxes out of the ABL and into the free troposphere. A caveat of our study was that it was limited to only one frontal passage event and thus, a general theory on the impact of fronts cannot be established. Future work should be able to incorporate multiple frontal passages over a region. The presence of the elongated band of $\mathrm{CO}_{2}$ along the frontal boundary can be tested for multiple events. Repeatable patterns of horizontal and vertical transport as seen in this case can be tested and quantified.

\section{Data Availability Statement}

CarbonTracker (CT-NRTv2017x) results are provided by NOAA ESRL, Boulder, Colorado, United States, from the website at (http://carbontracker.noaa.gov). Computing resources were provided by the NASA High-End Computing (HEC) Program through the NASA Advanced Supercomputing (NAS) Division at Ames Research Center. The WRF-Chem model output used for the current study is available at (https:// www.datacommons.psu.edu/commonswizard/MetadataDisplay.aspx?Dataset=6239).

\section{Acknowledgments}

Primary funding for this research was provided by NASA's Earth Sciences Division as part of the ACT-America Earth Venture Suborbital mission (grant NNX15AG76G to Penn State). ACT-America aircraft datasets for this research are available at Oak Ridge National Laboratory DAAC (Davis et al., 2018). Co-author S. Pal was partly supported by the NASA Grant 80NSSC19K0730. We thank M. P. Butler at the Pennsylvania State University for generating the codes that incorporate the global modeled $\mathrm{CO}_{2}$ mole fractions into the regional model with the conservation of mass (Lauvaux, 2020).

\section{References}

Agustí-Panareda, A., Diamantakis, M., Massart, S., Chevallier, F., Muñoz-Sabater, J., Barré, J., et al. (2019). Modeling CO2 weather-Why horizontal resolution matters. Atmospheric Chemistry and Physics Discussions, 19, 7347-7376. https://doi.org/10.5194/acp-2019-177

Bakwin, P. S., Davis, K. J., Yi, C., Wofsy, S. C., Munger, J. W., Haszpra, L., \& Barcza, Z. (2004). Regional carbon dioxide fluxes from mixing ratio data. Tellus B: Chemical and Physical Meteorology, 56(4), 301-311. https://doi.org/10.3402/tellusb. v56i4.1644610.1111/j.1600-0889.2004.00111.x

Ballav, S., Patra, P. K., Takigawa, M., Ghosh, S., De, U. K., Maksyutov, S., et al. (2012). Simulation of CO2 concentration over East Asia using the regional transport model WRF-CO2. Journal of the Meteorological Society of Japan, 90(6), 959-976. https://doi.org/10.2151/ jmsj.2012-607

Bastos, A., O'Sullivan, M., Ciais, P., Makowski, D., Sitch, S., Friedlingstein, P., et al. (2020). Sources of uncertainty in regional and global terrestrial CO2 exchange estimates. Global Biogeochemical Cycles, 34(2), 1-21. https://doi.org/10.1029/2019GB006393

Berrisford, P., Kållberg, P., Kobayashi, S., Dee, D., Uppala, S., Simmons, A. J., et al. (2011). Atmospheric conservation properties in ERA-Interim. Quarterly Journal of the Royal Meteorological Society, 137(659), 1381-1399. https://doi.org/10.1002/qj.864

Butler, M. P., Lauvaux, T., Feng, S., Liu, J., Bowman, K. W., \& Davis, K. J. (2020). Atmospheric simulations of total column CO2 mole fractions from global to mesoscale within the carbon monitoring system flux inversion framework. Atmosphere, 11(8), 787. Retrieved from https://www.mdpi.com/779918. https://doi.org/10.3390/ATMOS11080787

Carvalho, D., Rocha, A., Gómez-Gesteira, M., \& Silva Santos, C. (2014). Comparison of reanalyzed, analyzed, satellite-retrieved and NWP modeled winds with buoy data along the Iberian Peninsula coast. Remote Sensing of Environment, 152, 480-492. https://doi. org/10.1016/j.rse.2014.07.017

Chan, D., Yuen, C. W., Higuchi, K., Shashkov, A., Liu, J., Chen, J., \& Worthy, D. (2004). On the CO2 exchange between the atmosphere and the biosphere: The role of synoptic and mesoscale processes. Tellus B: Chemical and Physical Meteorology, 56(3), 194-212. https://doi. org/10.3402/tellusb.v56i3.16424

Chen, F., \& Dudhia, J. (2001). Coupling an advanced land surface-hydrology model with the Penn State-NCAR MM5 modeling system. Part I: Model implementation and sensitivity. Monthly Weather Review, 129(4), 569-585. https://doi. org/10.1175/1520-0493(2001)129<0569:caalsh > 2.0.co;2 
Chen, H. W., Zhang, L. N., Zhang, F., Davis, K. J., Lauvaux, T., Pal, S., et al. (2019). Evaluation of regional CO2 mole fractions in the ECMWF CAMS real-time atmospheric analysis and NOAA carbon tracker near-real-time reanalysis with airborne observations from ACT-America field campaigns. Journal of Geophysical Research: Atmospheres, 124(14), 8119-8133. https://doi.org/10.1029/2018JD029992

Chevallier, F., Remaud, M., O'Dell, C. W., Baker, D., Peylin, P., \& Cozic, A. (2019). Objective evaluation of surface- and satellite-driven carbon dioxide atmospheric inversions. Atmospheric Chemistry and Physics, 19(22), 14233-14251. https://doi.org/10.5194/acp-19-14233-2019

Davis, K. J., Obland, M. D., Lin, B., Lauvaux, T., O'Dell, C. W., Meadows, B., et al. (2018). ACT-America: L3 merged in situ atmospheric trace gases and flask data, Eastern USA. ORNL Distributed Active Archive Center. https://doi.org/10.3334/ORNLDAAC/1593

Dee, D. P., Uppala, S. M., Simmons, A. J., Berrisford, P., Poli, P., Kobayashi, S., et al. (2011). The ERA-Interim reanalysis: Configuration and performance of the data assimilation system. Quarterly Journal of the Royal Meteorological Society, 137(656), 553-597. https://doi. org/10.1002/qj.828

Denning, a. S., Fung, I. Y., \& Randall, D. (1995). Latitudinal gradient of atmospheric CO2 due to seasonal exchange with land biota (Vol. 376), (No. 6537). https://doi.org/10.1038/376240a0

Díaz-Isaac, L. I., Lauvaux, T., \& Davis, K. J. (2018). Impact of physical parameterizations and initial conditions on simulated atmospheric transport and CO2 mole fractions in the US Midwest. Atmospheric Chemistry and Physics, 18(20), 14813-14835. https://doi.org/10.5194/ acp-18-14813-2018

Díaz Isaac, L. I., Lauvaux, T., Davis, K. J., Miles, N. L., Richardson, S. J., Jacobson, A. R., \& Andrews, A. E. (2014). Model-data comparison of MCI field campaign atmospheric CO2mole fractions. Journal of Geophysical Research: Atmospheres, 119(17), 10536-10551. https:// doi.org/10.1002/2014JD021593

Digangi, J. P., Choi, Y., Nowak, J. B., Halliday, H. S., \& Yang, M. M. (2018). ACT-America: L2 in situ atmospheric CO2, CO, CH4, and O3 concentrations, Eastern USA. ORNL Distributed Active Archive Center. https://doi.org/10.3334/ORNLDAAC/1556

Edenhofer, O., Pichs-Madruga, R., Sokona, Y., Kadner, S., Minx, J. C., Brunner, S., et al. (2014). Climate change 2014 mitigation of climate change. In Working group iii contribution to the fifth assessment report of the intergovernmental panel on climate change (p. 1454). Cambridge University Press. https://doi.org/10.1017/CBO9781107415416

Ekström, M., \& Gilleland, E. (2017). Assessing convection permitting resolutions of WRF for the purpose of water resource impact assessment and vulnerability work: A southeast Australian case study. Water Resources Research, 53(1), 726-743. https://doi. org/10.1002/2016WR019545

Enting, I. G., Trudinger, C. M., \& Francey, R. J. (1995). A synthesis inversion of the concentration and delta13 C of atmospheric CO2. Tellus B: Chemical and Physical Meteorology, 47(1-2), 35-52. https://doi.org/10.1034/j.1600-0889.47.issue1.5.x

Feng, S., Lauvaux, T., Davis, K. J., Keller, K., Zhou, Y., Williams, C., et al. (2019). Seasonal characteristics of model uncertainties from biogenic fluxes, transport, and large-scale boundary inflow in atmospheric CO2 simulations over North America. Journal of Geophysical Research: Atmospheres, 124(24), 14325-14346. https://doi.org/10.1029/2019JD031165

Feng, S., Lauvaux, T., Keller, K., Davis, K. J., Rayner, P., Oda, T., \& Gurney, K. R. (2019). A road map for improving the treatment of uncertainties in high-resolution regional carbon flux inverse estimates. Geophysical Research Letters, 46(22), 13461-13469. https://doi. org/10.1029/2019GL082987

Feng, S., Lauvaux, T., Newman, S., Rao, P., Ahmadov, R., Deng, A., et al. (2016). LA megacity: A high-resolution land-atmosphere modeling system for urban CO2 emissions. Atmospheric Chemistry and Physics Discussions, 16, 1-56. https://doi.org/10.5194/acp-2016-143

Friedlingstein, P., Jones, M. W., O'Sullivan, M., Andrew, R. M., Hauck, J., Peters, G. P., et al. (2019). Global carbon budget 2019. Earth System Science Data, 11(4), 1783-1838. https://doi.org/10.5194/essd-11-1783-2019

Geels, C., Doney, S. C., Dargaville, R., Brandt, J., \& Christensen, J. H. (2004). Investigating the sources of synoptic variability in atmospheric $\mathrm{CO} 2$ measurements over the Northern Hemisphere continents: A regional model study. Tellus B: Chemical and Physical Meteorology, 56(1), 35-50. https://doi.org/10.3402/tellusb.v56i1.16399

Geels, C., Gloor, M., Ciais, P., Bousquet, P., Peylin, P., Vermeulen, A. T., et al. (2007). Comparing atmospheric transport models for future regional inversions over Europe-Part 1: Mapping the atmospheric CO2 signals. Atmospheric Chemistry and Physics, 7(13), 3461-3479. https://doi.org/10.5194/acp-7-3461-2007

Gurney, K. R., Law, R. M., Denning, A. S., Rayner, P. J., Baker, D., Bousquet, P., et al. (2002). Toward robust regional estimates of CO2 sources and sinks using atmospheric transport models. Nature, 415(6872), 626-630. https://doi.org/10.1038/415626a

Houghton, R. A., House, J. I., Pongratz, J., van der Werf, G. R., DeFries, R. S., Hansen, M. C., et al. (2012). Carbon emissions from land use and land-cover change. Biogeosciences, 9(12), 5125-5142. https://doi.org/10.5194/bg-9-5125-2012

Houweling, S., Aben, I., Breon, F.-M., Chevallier, F., Deutscher, N., Engelen, R., et al. (2010). The importance of transport model uncertainties for the estimation of $\mathrm{CO} 2$ sources and sinks using satellite measurements. Atmospheric Chemistry and Physics, 10(20), 9981-9992. https://doi.org/10.5194/acp-10-9981-2010

Huntzinger, D. N., Michalak, A. M., Schwalm, C., Ciais, P., King, A. W., Fang, Y., et al. (2017). Uncertainty in the response of terrestrial carbon sink to environmental drivers undermines carbon-climate feedback predictions. Scientific Reports, 7(1), 4765. https://doi. org/10.1038/s41598-017-03818-2

Hurwitz, M. D., Ricciuto, D. M., Bakwin, P. S., Davis, K. J., Wang, W., Yi, C., \& Butler, M. P. (2004). Transport of carbon dioxide in the presence of storm systems over a northern Wisconsin Forest. Journal of the Atmospheric Sciences, 61(5), 607-618. https://doi.org/10.11 75/1520-0469(2004)061<0607:tocdit>2.0.co;2

Iacono, M. J., Delamere, J. S., Mlawer, E. J., Shephard, M. W., Clough, S. A., \& Collins, W. D. (2008). Radiative forcing by long-lived greenhouse gases: Calculations with the AER radiative transfer models. Journal of Geophysical Research, 113(D13). https://doi org/10.1029/2008JD009944

Kain, J. S. (2004). The Kain-Fritsch convective parameterization: An update. Journal of Applied Meteorology, 43(1), 170-181. https://doi. org/10.1175/1520-0450(2004)043<0170:tkcpau>2.0.co;2

Keppel-Aleks, G., Wennberg, P. O., \& Schneider, T. (2011). Sources of variations in total column carbon dioxide. Atmospheric Chemistry and Physics, 11(8), 3581-3593. https://doi.org/10.5194/acp-11-3581-2011

Klemp, J. B. (2006). Advances in the WRF model for convection-resolving forecasting. Advances in Geosciences, 7, 25-29. https://doi. org/10.5194/adgeo-7-25-2006

Lauvaux, T. (2020). Psu-inversion/WRF_boundary_coupling: WRF Boundary Coupling (Tracer mode—Chemistry). https://doi.org/10.5281/ ZENODO.3832214

Lauvaux, T., \& Davis, K. J. (2014). Planetary boundary layer errors in mesoscale inversions of column-integrated CO2 measurements. Journal of Geophysical Research: Atmospheres, 119(2), 490-508. https://doi.org/10.1002/2013JD020175 
Lauvaux, T., Schuh, A. E., Uliasz, M., Richardson, S., Miles, N., Andrews, A. E., et al. (2012). Constraining the CO2 budget of the corn belt: Exploring uncertainties from the assumptions in a mesoscale inverse system. Atmospheric Chemistry and Physics, 12(1), 337-354. https://doi.org/10.5194/acp-12-337-2012

Law, R. M., Peters, W., Rödenbeck, C., Aulagnier, C., Baker, I., Bergmann, D. J., et al. (2008). TransCom model simulations of hourly atmospheric CO2: Experimental overview and diurnal cycle results for 2002. Global Biogeochemical Cycles, 22(3). https://doi. org/10.1029/2007GB003050

Law, R. M., Rayner, P. J., Denning, A. S., Erickson, D., Fung, I. Y., Heimann, M., et al. (1996). Variations in modeled atmospheric transport of carbon dioxide and the consequences for CO 2 inversions. Global Biogeochemical Cycles, 10(4). https://doi.org/10.1029/96GB01892

Lee, T. R., De Wekker, S. F. J., Andrews, A. E., Kofler, J., \& Williams, J. (2012). Carbon dioxide variability during cold front passages and fair weather days at a forested mountaintop site. Atmospheric Environment, 46, 405-416. https://doi.org/10.1016/j.atmosenv.2011.09.068

Le Quéré, C., Andrew, R. M., Friedlingstein, P., Sitch, S., Hauck, J., Pongratz, J., et al. (2018). Global Carbon Budget 2018. Earth System Science Data, 10(4), 2141-2194. https://doi.org/10.5194/essd-10-2141-2018

Li, Y., Barth, M. C., \& Steiner, A. L. (2019). Comparing turbulent mixing of atmospheric oxidants across model scales. Atmospheric Environment, 199, 88-101. https://doi.org/10.1016/j.atmosenv.2018.11.004

Nakanishi, M., \& Niino, H. (2006). An improved Mellor-Yamada Level-3 model: Its numerical stability and application to a regional prediction of advection fog. Boundary-Layer Meteorology, 119(2), 397-407. https://doi.org/10.1007/s10546-005-9030-8

Pal, S., \& Davis, K. J. (2020). ACT-America Field Campaign Catalogue, Oak Ridge, Tennessee: ORNL DAAC. https://actamerica.ornl.gov/ campaigns.html\#SUMMER_2016

Pal, S., Davis, K. J., Lauvaux, T., Browell, E. V., Gaudet, B. J., Stauffer, D. R., et al. (2020). Observations of greenhouse gas changes across summer frontal boundaries in the Eastern United States. Journal of Geophysical Research: Atmospheres, 125(5), e2019JD030526. https:// doi.org/10.1029/2019JD030526

Parazoo, N. C., Denning, A. S., Kawa, S. R., Corbin, K. D., Lokupitiya, R. S., \& Baker, I. T. (2008). Mechanisms for synoptic variations of atmospheric CO2 in North America, South America and Europe. Atmospheric Chemistry and Physics, 8(23), 7239-7254. https://doi. org/10.5194/acp-8-7239-2008

Patra, P. K., Law, R. M., Peters, W., Rödenbeck, C., Takigawa, M., Aulagnier, C., et al. (2008). TransCom model simulations of hourly atmospheric CO2: Analysis of synoptic-scale variations for the period 2002-2003. Global Biogeochemical Cycles, 22(4). https://doi. org/10.1029/2007GB003081

Pauluis, O., Czaja, A., \& Korty, R. (2008). The global atmospheric circulation on moist isentropes. Science, 321(5892), 1075-1078. https:// doi.org/10.1126/science.1159649

Peters, W., Jacobson, A. R., Sweeney, C., Andrews, A. E., Conway, T. J., Masarie, K., et al. (2007). An atmospheric perspective on North American carbon dioxide exchange: CarbonTracker. Proceedings of the National Academy of Sciences, 104(48), 18925-18930. https://doi. org/10.1073/pnas.0708986104

Peylin, P., Baker, D., Sarmiento, J., Ciais, P., \& Bousquets, P. (2002). Influence of transport uncertainty on annual mean and seasonal inversions of atmospheric CO2 data. Journal of Geophysical Research, 107(19), 4385. https://doi.org/10.1029/2001JD000857

Sarrat, C., Noilhan, J., Dolman, A. J., Gerbig, C., Ahmadov, R., Tolk, L. F., et al. (2007). Atmospheric CO2 modeling at the regional scale: An intercomparison of 5 meso-scale atmospheric models. Biogeosciences, 4(6), 1115-1126. https://doi.org/10.5194/bg-4-1115-2007

Schuh, A. E., Jacobson, A. R., Basu, S., Weir, B., Baker, D., Bowman, K., et al. (2019). Quantifying the Impact of atmospheric transport uncertainty on CO 2 surface flux estimates. Global Biogeochemical Cycles, 33(4), 484-500. https://doi.org/10.1029/2018GB006086

Skamarock, W., Klemp, J., Dudhi, J., Gill, D., Barker, D., Duda, M., et al. (2008). A description of the advanced research WRF version 3Technical Report (June) (Vol. 113). https://doi.org/10.5065/D6DZ069T

Skeie, R. B., Berntsen, T. K., Myhre, G., Tanaka, K., Kvalevåg, M. M., \& Hoyle, C. R. (2011). Anthropogenic radiative forcing time series from pre-industrial times until 2010. Atmospheric Chemistry and Physics, 11(22), 11827-11857. https://doi.org/10.5194/acp-11-11827-2011

Tans, P. P., Fung, I. Y., \& Takahashi, T. (1990). Observational contrains on the global atmospheric Co2 budget. Science, 247(4949), 14311438. https://doi.org/10.1126/science.247.4949.1431

Thompson, G., Field, P. R., Rasmussen, R. M., \& Hall, W. D. (2008). Explicit forecasts of winter precipitation using an improved bulk microphysics scheme. Part II: Implementation of a new snow parameterization. Monthly Weather Review, 136(12), 5095-5115. https:// doi.org/10.1175/2008MWR2387.1

Uliasz, M. (1994). Lagrangian particle dispersion modeling in mesoscale applications. In Smr (Vol. 760, p. 23).

Wang, J.-W., Denning, A. S., Lu, L., Baker, I. T., Corbin, K. D., \& Davis, K. J. (2007). Observations and simulations of synoptic, regional, and local variations in atmospheric CO2. Journal of Geophysical Research, 112(4). https://doi.org/10.1029/2006JD007410

Xiao, J., Davis, K. J., Urban, N. M., \& Keller, K. (2014). Uncertainty in model parameters and regional carbon fluxes: A model-data fusion approach. Agricultural and Forest Meteorology, 189-190, 175-186. https://doi.org/10.1016/j.agrformet.2014.01.022 